\title{
Metrology for the Semiconductor Industry
}

\author{
Robert I. Scace
}

U.S. DEPARTMENT OF COMMERCE National Institute of Standards and Technoiogy Electronics and Electrical Enerineering Laboratory Gaithersburg, MD 20899 



\section{Metrology for the Semiconductor Industry}

\section{Robert I. Scace}

U.S. DEPARTMENT OF COMMERCE National Institute of Standards and Technology Electronics and Electrical Engineering Laboratory Gaithersburg, MD 20899

September 1991

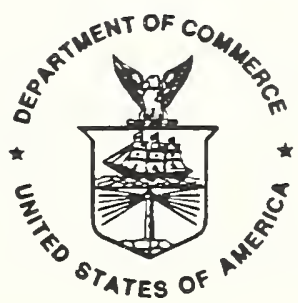

U.S. DEPARTMENT OF COMMERCE Robert A. Mosbacher, Secretary MATONAL INSTIUTE OF STANDARDS AND TECHNOLOGY

John W. Lyons, Director 



\section{TABLE OF CONTENTS}

PREFACE $\ldots \ldots \ldots \ldots \ldots \ldots \ldots \ldots \ldots \ldots \ldots \ldots$ iv

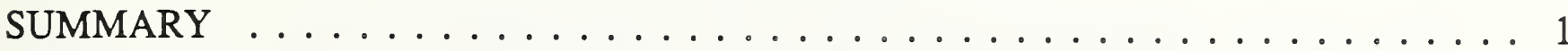

DESCRIPTION OF THE TECHNOLOGY . . . . . . . . . . . . . . 3

Materials ......................... 4

Manufacturing ...................... 5

Market Environment . . . . . . . . . . . . . . . . . . 7

ECONOMIC SIGNIFICANCE AND

THE U.S. INTERNATIONAL COMPETITIVE POSITION . . . . . . . . . . . . 8

Industry structure $\ldots \ldots \ldots \ldots \ldots \ldots \ldots \ldots \ldots$

KEY TECHNOLOGIES . . . . . . . . . . . . . . . . . . . 11

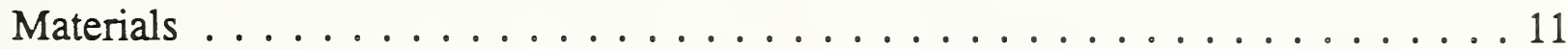

Silicon ........................... 11

Compound semiconductors . . . . . . . . . . . . . . 11

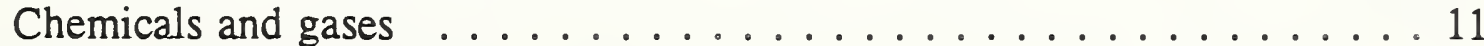

Plastic molding materials . ................. 12

Photomasks and mask substrates . . . . . . . . . . . . 12

Manufacturing Issues . . . . . . . . . . . . . . . . . . . 12

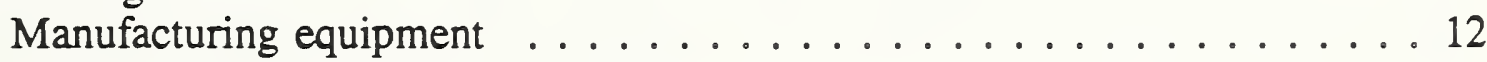

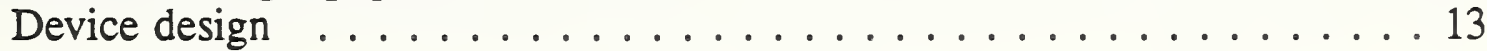

Process control ........................ . 13

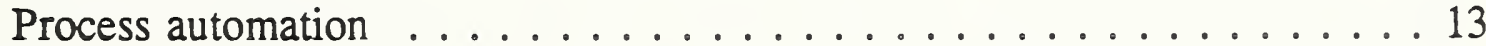

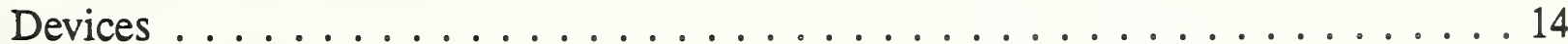

Advanced microcircuits . . . . . . . . . . . . . . . 14

Optoelectronics . . . . . . . . . . . . . . . . . 17

Microwave ICs . . . . . . . . . . . . . . . . . 18

Power devices . . . . . . . . . . . . . . . . . . . . 19

TRENDS IN THE TECHNOLOGY . . . . . . . . . . . . . . . . . . . . . . . . . 19

U.S. INDUSTRY GOALS . . . . . . . . . . . . . . . . . . 26

MEASUREMENTS TO MEET THESE GOALS . . . . . . . . . . . . . . . . . . 27

EVIDENCE OF NEED FOR IMPROVED MEASUREMENTS . . . . . . . . . . . . . 28

MEASUREMENTS NEEDED . . . . . . . . . . . . . . . . . 30

Materials . . . . . . . . . . . . . . . . . . 31

Processes . . . . . . . . . . . . . . . . . . . . . . . 35

General purpose techniques . . . . . . . . . . . . . . . . 37 


\section{PREFACE}

This report reviews the metrological needs of the semiconductor industry and its infrastructure, the materials and equipment industries that supply it, for the remainder of the present decade to the extent that they now can be foreseen. The text will also appear as one chapter of a larger assessment of needs for the electronics industry to be published later in 1991.

Only a needs assessment is included here. The manner in which the needs can be met is not discussed, largely because the task of such a magnitude that no single organization can possibly do the necessary research and development on the time scale that the industry requires. Clearly, there is ample opportunity for contributions from universities, industrial laboratories, and government organizations such as NIST.

One principal purpose for preparing this report is to guide the planning of NIST's activities. Identification of the needs is only the first step in planning. Priorities must also be set. These depend on feedback from the industries that need the measurements described here, on knowledge of the work of others who may be working on related topics, and on the resources available to NIST. So much must be done that the luxury of duplicated efforts cannot be afforded.

I hope that wide distribution of this report will encourage others to do two things:

- advise NIST on the urgency of the industry's needs, and

- inform NIST of related research currently under way in their laboratories so that NIST can set its priorities intelligently. I can be reached at the address below.

This report draws on numerous recent publications of workshops and technology forecasts that are footnoted in the text. Early drafts were reviewed by others in the industry whose comments and advice are gratefully acknowledged. In particular, I would like to thank W. Murray Bullis (Materials and Metrology), Robert M. Burger (Semiconductor Research Corporation), Terry Francis (Applied Materials), Dan Hutcheson (VLSI Research), Graydon Larrabee (Texas Instruments), and James T. Yeh (IBM) for their extensive suggestions and their encouragement.

Robert I. Scace, Director

Microelectronics Programs

National Institute of Standards and Technology

Building 220, Room B358

Gaithersburg, MD 20899

Phone 301-975-2220

Fax 301 975-4091

E-mail scace@micf.nist.gov 


\title{
METROLOGY FOR THE SEMICONDUCTOR INDUSTRY
}

\author{
Robert I. Scace \\ National Institute of Standards and Technology \\ Gaithersburg, MD 20899
}

\section{SUMMARY}

Electronics affects every aspect of life today. Electronic systems are integral parts of the nation's defense, communication systems, transportation, medical care, banking, manufacturing, entertainment, etc. Electronics is one of the largest manufacturing segments of the U.S. economy, amounting to some $\$ 254$ billion in 1989 and growing at 4.7 percent annually ${ }^{1}$. It employs 2.03 million people, more than twice as many as the chemical industry, which is slightly larger in dollars. Semiconductor devices are absolutely essential components of all electronic products today. Without semiconductors, electronic products and systems cannot be made or operated. The U.S. semiconductor industry produced $\$ 29$ billion of products in $1989^{2}$ (42 percent of the world market) and is growing at a rate of 16 percent annually. Japan produced $\$ 33$ billion, 46 percent of the world market. However, from 1985 to 1989 Japan gained 11 percentage points of the world market at U.S. expense. U.S. suppliers sold $\$ 4.5$ billion of semiconductor manufacturing equipment in 1989, a 48 percent share of the world market.

The competitive problems faced by the U.S. semiconductor-related industries are well known. Many significant studies, including those by National Research Council (NRC) on Advanced Processing of Electronic Materials in the United States and Japan (1986), by the Defense Science Board (1987), and most recently A Strategic Industry at Risk (1989) and Preserving the Vital Base (1990) from the National Advisory Committee on Semiconductors, have emphasized the seriousness of the U.S. deficiency in semiconductor manufacturing technologies. Worldwide, the $\$ 71$ billion semiconductor device market, the $\$ 9.4$ billion semiconductor manufacturing equipment market, and the $\$ 9.5$ billion semiconductor materials market are at stake. Japanese companies, while highly competitive with one another, are the beneficiaries of a variety of well-funded long-term programs of generic technological development initiated by their government. The U.S. has responded by establishing SEMATECH, a

\footnotetext{
${ }^{1}$ For comparison, in 1989 the motor vehicles, parts, and accessories industry was about $\$ 240$ billion and not growing, steel was about $\$ 60$ billion and declining, and aerospace was $\$ 120$ billion, growing at about 7 percent annually. Electronics industry data from 1990 Electronic Market Data Book, Marketing Services Department, Electronic Industries Association (1990). Other industry data from 1990 U.S. Industrial Outlook, International Trade Administration, U.S. Department of Commerce (1990).

${ }^{2}$ Data from this point to the end of the paragraph are from VLSI Research, and include production by both captive and merchant manufacturers.
} 
consortium to rebuild U.S. excellence in semiconductor manufacturing. About half of its funds come from the 14 member companies and half from the U.S. government.

Today's sub-micrometer integrated circuit technology is only achievable by pressing science and skill to very expensive limits. The breadth of science and technology used in semiconductor manufacturing is rapidly expanding. Problems of imperfect understanding and inability to measure what is being done abound. Integrated circuits ${ }^{3}$ today are built with great ingenuity by using very complex processes to deposit and remove surface films. The chemistry and physics of these processes are not well understood. The surfaces on which films are deposited affect both the deposition processes and the properties of the semiconductor devices in ways that are evident but not understood; these effects are becoming ever more significant. A clear view of what is being made requires electron microscopes, but accurate dimensional measurements with these are not now possible. Soon it will be necessary to create ultra-small patterns using $\mathrm{x}$-rays or other new techniques that will require totally new measurements. Control of contamination from particles and stray impurities is pressing the limits of measurement and control. As device dimensions shrink, the details of their behavior change significantly. Previously negligible effects become important, and must be accounted for in engineering design. New device theory and computer models of device behavior are needed.

Semiconductor manufacturing is a measurement-intensive business. It has been estimated that about one quarter of the cost of making semiconductor devices is in measurement ${ }^{4}$. As semiconductor devices become smaller and smaller and chips become more and more complex, the demands on measurement technology increase. Better sensitivity, improved accuracy, totally new measurements, and the pressure to automate the manufacturing process are all needs that must be met. New materials and new processes bring with them new measurement problems that must be solved.

Many kinds of process equipment contain measurement systems to control their own operation. The strong present-day move to greater automation means that these measurements have a very great effect on the overall control of the entire manufacturing process. It is difficult enough to measure many of the process variables with human aid. It is much more difficult to obtain accurate data without it. All of these factors add greatly to the challenge that NIST faces to support the processing equipment, materials, and device manufacturing industries with the measurements that are desperately needed.

These needs are enumerated in the reports of recent workshops and technology assessments, which almost invariably include requests for NIST help in finding solutions to them. ${ }^{5}$

\footnotetext{
${ }^{3}$ Integrated circuit - a semiconductor electronic device incorporating a number of individual transistors or other individual components, all formed in a single piece of semiconducting material and interconnected to perform a useful electronic function. Sometimes called a chip or an IC.

${ }^{4}$ Private communications from senior technical staff members of three large semiconductor device manufacturers. This figure is a minimum; estimates ranged up to one third.

${ }^{5}$ These include Semiconductor Research Corporation Technology Trends Assessment, Wild Dunes, SC, September 6 8, 1989; SEMICON/Southwest 90 Technical Conference Proceedings: Metrology for Advanced Materials/Process Characterization, Dallas, TX, January 31-February 1, 1990; Semiconductor Research Corporation Topical Research Conference on Metrology for Semiconductor Manufacturing, Santa Fe, NM, February 21-22, 1990; and Workshop on Silicon Materials for MEGA-IC Applications, New Orleans, LA, January 30-31, 1991.
} 


\section{DESCRIPTION OF THE TECHNOLOGY ${ }^{6}$}

Semiconductor technology continues to advance on a wide front. For example, the scale of dimensions used in semiconductor manufacturing is rapidly shrinking, for two reasons. Smaller devices are faster, and more of them can be put on one chip. Both of these results allow electronic systems to have greater levels of performance. Table 1 shows this evolution.

\section{Table 1}

\section{Evolution of Electronic Devices}

Dimension
centimeter $(\mathrm{cm})$
millimeter $(\mathrm{mm})$
micrometer $(\mu \mathrm{m})$
sub-micrometer

$$
\text { Technology }
$$

Vacuum Tube

Transistors

Integrated Circuits

Advanced Integrated Circuits
Time

$1925-1960$

$1950-$

today

1990 s

Semiconductor manufacturing is a complex sequential process of up to 500 steps. Most of these steps cause irreversible changes, so if a processing error occurs during any step the wafers are useless. Measurement is not always possible after every step. Even when measurements are possible, inaccuracies can cause defective material to appear to be within process control limits, thus leading to spending money on further processing of material that is in fact scrap. Measurement uncertainties also limit the degree of process control that is possible.

Each new generation of semiconductor devices presents manufacturing difficulties that must be overcome. Yet the first company to sell a new device has the great advantage of being able to get a high price for the product, until the entry of competitors in the market starts price competition. In deciding when to enter the market, the advantage of early entry must be weighed against the consequences of possible loss of control of the process and inability to deliver the product.

Improved measurement allows better control over the process and lets one get to the market earlier. Product yields at the early stages of manufacturing are typically from five to 15 percent. Experience with the new product usually improves process control so the yield rises rapidly (and costs drop in proportion). This is a further incentive for early product introduction. Early high prices help pay the costs of low yield. By the time the competition enters the market, the first producer has his costs well in hand and can make money even at reduced prices. The later entries must suffer low yields and at the same time low prices until yields can be raised. This pattern has been repeated many times in the semiconductor industry and is well known to both the winners and the losers in the market.

\footnotetext{
${ }^{6}$ A more extensive description of semiconductor technology for the interested lay person is contained in Robert I. Scace, Semiconductor Technology for the Non-Technologist, second edition, NIST IR-90-4414, published by the National Institute of Standards and Technology (September, 1990).
} 


\section{Materials}

Semiconductor devices are made in a very wide spectrum of types to serve varying applications. All, however, depend on the properties of semiconducting ${ }^{7}$ materials for their operation. By far the majority of semiconductor devices are made from silicon, which is one of the most abundant elements. Certain specialized devices are made from compound semiconductors. Compound semiconductors are usually formed of arsenic, antimony, phosphorus, aluminum, gallium, or indium in various combinations, though compounds of many other materials are semiconductors having specialized uses. Gallium arsenide ( $\mathrm{GaAs})$ is the most commonly used compound semiconductor material. Table 2 shows some attributes of silicon and the more common compound semiconductor materials.

Table 2

\section{Silicon Compared with Compound Semiconductors}

Number of starting elements Availability of starting materials Available purity of starting elements

Speed of devices

Ease of fabrication

Ability to make light

Ability to detect light

Typical materials

Silicon
one
very abundant
excellent

fast

difficult

no

yes

silicon
Compound Semiconductors two to six scarce (aluminum less so) fair to poor

2-3 times faster very difficult

\section{yes \\ yes}

gallium arsenide gallium aluminum arsenide indium phosphide

Regardless of the semiconductor material that is used, devices can be made only if the material is extraordinarily pure. Typically, semiconductor grade silicon may contain oxygen at a few parts per million, carbon at less than one part per million, and metallic impurity elements at the part per trillion level ${ }^{8}$. Certain electrically-active impurities (boron, phosphorus, antimony, and aluminum) are controlled to a few tens of parts per trillion. As the silicon is processed into devices, these latter four elements (called dopants, to distinguish them from all other impurities) are intentionally added under strict controls to adjust the electrical properties of the

\footnotetext{
${ }^{7}$ Semiconducting materials are so called because their electrical conducting properties are not like metals (conductors) or insulators (non-conductors), but somewhere between. Their important property is that small amounts of certain elements, if present in the semiconductor, dramatically affect the electrical conduction of the semiconductor. This allows the electrical properties of the material to be controlled over an extremely wide range.

${ }^{8}$ To get an idea of what this means, consider that there are 5 billion people on earth. At an average weight of 150 pounds, the world's population weighs 0.75 trillion pounds. If you diet and lose 7.5 pounds, you will have lost 10 parts per trillion of the weight of the entire population of the world.
} 
various regions of silicon that form the finished product. The dopants are themselves in a very highly pure state, to avoid unwanted impurities being inadvertently added to the silicon.

Various other chemicals are used in semiconductor device manufacturing. These include solvents (alcohols, acetone, etc.), acids (nitric, sulfuric, hydrofluoric, etc.), gases (nitrogen, oxygen, hydrogen, argon, and numerous specialized gases), and water. To consider the latter as a chemical may seem surprising, but, like the rest of these materials, it must be supplied in very pure condition to avoid contamination of the silicon. Pure water is an aggressive solvent.

\section{Manufacturing}

Semiconductor manufacturing is done in special facilities (clean rooms) in which the temperature, humidity, and particulate contamination levels are tightly controlled. All equipment and facilities are specially designed to avoid contamination. Workers are dressed in special clothing, because people continually shed particles from the skin. This fanatical attention to cleanliness is necessary to avoid contamination of the silicon. Even a particle smaller than a hundredth as large as the cross-section of a hair can cause an integrated circuit to be defective. Pollen, germs, smoke, and other common particles are much larger in size.

The process ${ }^{9}$ of making semiconductor devices starts with a very flat, round wafer of silicon. The material supplier has made the wafer from a larger ingot typically three or four feet long and composed of a single crystal ${ }^{10}$ of silicon. The basic electrical properties of the wafer are controlled by the material supplier to meet the device maker's specifications. The wafer is typically 100 to $200 \mathrm{~mm}$ (4 to $8 \mathrm{in}$.) in diameter and flat to within less than $3 \mu \mathrm{m}$ (micrometer). This departure from flatness would, if the wafer were the size of a baseball field, amount to only an eighth of an inch.

In addition, the structural perfection of the wafer is important. That is, every atom in the wafer should be in its proper position with no atomic sites unoccupied. This ideal can be closely approached but not entirely met. The presence of oxygen leads to an imperfection called oxygen-induced stacking faults, for example. These and other crystalline imperfections at too great a concentration cause problems in device manufacture. So do minute departures from flatness on an atomic scale, called micro-roughness. This fault has only been known to be important in recent years. Its causes and cures, and its measurement, are still imperfectly understood. And, like everything else used in making semiconductor devices, wafer surfaces must be free of particulate contamination.

The device process consists of forming various films in or on the wafer surface, creating patterns in each film as it is created. This builds a structure of perhaps 20 different layers, all

\footnotetext{
${ }^{9}$ This description is of a silicon integrated circuit process. Other kinds of devices are made using similar tools and techniques, though the details vary considerably.

${ }^{10}$ Most solids are composed of many tiny crystals, within which the atoms are arranged in a periodic, three-dimensional array. These crystals are not normally observable except under a microscope. Large crystals of many materials occur naturally, and are often quite beautiful. They can also be grown artificially by several methods. Silicon is used in the form of a single crystal because the boundaries between adjoining crystals have different electrical and processing behavior that would interfere with successful integrated circuit manufacture.
} 
interconnected laterally and vertically to form a complex network of individual transistors ${ }^{11}$ and electrical connections among them. Films may be of insulating materials such as silicon dioxide (quartz) or of conducting materials such as heavily-doped silicon or metals. They are applied by evaporation or sputtering in a vacuum (for metals), or by chemical processes involving reactions promoted in a mixture of gases by heat or electrical energy in a partial vacuum.

The patterns are formed by first coating the surface of the wafer with a photoresist. This is a paint-like material that, when exposed to ultraviolet light through a patterned glass plate, forms on the wafer surface an image of the pattern on the plate. The process is much like taking a photograph, except that the image in this case is either black (resist remains after development) or white (no resist). The difficulties in this process can be appreciated by considering that the details in the image are as small as $0.6 \mu \mathrm{m}$ (less than $1 / 100$ the diameter of a hair), that a pattern must align with those formed earlier to a tenth of that amount, and that the machine that does this work has about a quarter of a second to align and expose each image. (Lenses that can form such detailed images can do so only over an area a little more than half an inch square, so the process must be repeated many times to cover the entire wafer.) After the pattern is reproduced in the photoresist, leaving resist in some places and not in others, the film thus exposed can be removed by chemical etching, covered by material added in several ways, or modified by ion implantation. The rest of the resist is then stripped away, and the next film is applied. The procedure of this paragraph is repeated as many times as necessary, typically about 20 in more advanced products.

The last few layers form the electrical connections among the transistors that comprise the circuit, and also provide small connection pads around the edge of each completed integrated circuit. The circuits may now receive an initial electrical test by contacting the pads with an array of needles. The location of defective circuits is identified so they will not be processed further. Depending on the size of each circuit and the size of the wafer, there may be from 70 to several hundred circuits in a regular pattern on the wafer. The individual circuits are then separated by cutting the wafer with a fine diamond saw.

At this point, the integrated circuit (or other device) is electrically completed but is still exposed to contamination and physical damage. It must be enclosed in a protective "package", which may be a metal and ceramic enclosure or molded from plastic. In addition to protecting the silicon chip, the package provides more robust electrical connections to the circuit and a pathway for removing the heat generated by the device. The latter is crucial for large ICs and for any other devices that handle appreciable amounts of power.

Complete final testing is only possible after the chip has been packaged. This is the product that is sold to the customer. Any effect of the package on the performance of the device, which may be slight or great, must be taken into account in the device maker's specifications for the device. More important for power device types is the heat dissipation provided by the package. Extensive testing heats the chip, and without the package the device can become too hot and be damaged. The economics of chip and final testing is changing. Increased attention to process control raises yields sufficiently in some cases to make the cost of such

\footnotetext{
${ }^{11}$ Transistors are the elementary building blocks of nearly all electronic circuits, including especially integrated circuits. Transistors function as switches (either they are on or they are off), or as amplifiers, making small electrical signals larger.
} 
testing unattractive. The payback is better for increased measurement early in the process, which leads to making the product right the first time.

\section{Market Environment}

Semiconductor devices have been made commercially for over 35 years. The course of development started with making individual transistors and diodes (which early replaced most vacuum tubes in electronic equipment), continued with the integration of these devices into simple integrated circuits containing only a few transistors, and advanced to the manufacture of today's integrated circuits that contain as many as ten million transistors. ICs containing well over 200 million transistors are in development. Throughout this period, the cost of semiconductors per electronic function that they provide has dropped dramatically.

The driving force behind this remarkable accomplishment has been the demand of electronic systems manufacturers and their customers for products providing more and more power, speed, convenience, etc., all at low costs. The growth in power of computers stems directly from this process. Semiconductor device makers have met this demand by making the individual devices smaller and smaller, and packing more of them on a single piece of silicon. Synergy between the computer industry and the integrated circuit makers has been essential. Computers were necessary to design integrated circuits, which quickly became far too complicated to design manually. The resulting ICs allowed more powerful computers to be made, which were used for the next generations of circuit design, and so on. Today, almost without exception all semiconductor manufacturing equipment contains computer-based controls. The equipment is tied together and directed by computers. Material flow and process control in semiconductor plants is managed by computers. For many years the final testing of the product has only been possible with computer-controlled equipment.

The march toward smaller and smaller features in increasingly complex circuits has brought with it very high costs. Clean room space costs from $\$ 2000$ to $\$ 7000$ a square foot, and is expensive to operate and maintain. Equipment is both expensive and quickly becomes obsolete by advances in the technology. IC fabrication facilities now cost $\$ 500$ million or more each for a commercially viable scale of operation, and the billion-dollar plant is on the horizon. Individual processes are more complex, and there are more of them. The allowable variances in materials properties and in process execution are becoming smaller.

The steady thrust toward greater and greater numbers of increasingly smaller devices on chips that do ever more complex things, made cheaper with more expensive facilities and tools in fierce competition with every advanced nation in the world, must eventually approach some physical limits. In fact, the rate at which circuit complexity increases has slowed somewhat. For years circuits doubled in complexity every two years. Lately it has taken three years, and soon it will require four. But at least until the end of this decade there seems to be no insuperable obstacle to continuation of these trends.

Nevertheless, one should bear in mind that the great majority of electronic products are manufactured using semiconductor devices that are not made with leading-edge technology. Logic circuits, such as those used in desktop computers, are only about a tenth as complex (in terms of the number of transistors in a single IC) as the most advanced memory devices. A very large part of the world's electronic work is done with systems that use devices of older generations. They are well-proven, cheap, and perfectly adequate. In this context, advanced technolo- 
gy allows these older products to be made inexpensively and reliably in great volumes. Products that are very difficult to make today at any cost become easy to manufacture with the passage of a few years. They become the cash cows that help pay for the newest and latest advances.

\section{ECONOMIC SIGNIFICANCE AND THE U.S. INTERNATIONAL COMPETITIVE POSITION}

Semiconductor technology is unique in being not only the foundation of a large industry in the U.S. and the world but the key technology required for making all electronic systems. Figure 1 illustrates the point. The value of electronic products in 1989 was $\$ 270$ billion in this country and about the same again for the rest of the world. These systems in turn are used by every human activity in the industrial world. "Over the past three decades, no single field of science or engineering has had a greater impact on the national productivity and quality of life than has semiconductor electronics. Semiconductors have revolutionized the communication, entertainment, and transportation industries, and created the computer industry. ${ }^{12}$ Without semiconductors we would have little or no communication, transportation, medical care, entertainment, banking, defense, etc., etc., as we know them today. We have become dependent on electronics and thus dangerously vulnerable as a nation to the loss of the semiconductor industry. Just such a loss is occurring.

"Information, communications, computation, and control technologies are also crucial elements of our national defense, both in its management and its weapons systems. Because it is so pervasive, this area of engineering can be considered basic to all others as the world moves into the information age. ${ }^{13}$

Table 3 illustrates the trend in market share. The U.S. lost 11 percentage points to the Japanese in market share from 1985 to 1989 . There is no indication that these trends are changing. We are competing effectively with the Japanese and holding our position in basic research, but in product implementation we are being beaten to the market. It may be argued that an industry that continues to increase in sales absolutely by doubling every five years cannot be in too much trouble, but when one's chief competitor doubles in size every three years there is cause for serious concern.

\section{Industry structure}

An understanding of the semiconductor industry can only be gained by considering not only the semiconductor device manufacturers and their products but the key parts of the industrial infrastructure that support semiconductor manufacturing. The evolution of semiconductor technology affects the device makers and the materials and equipment companies alike. All must work together, and do. The discussion that follows thus deals first with the suppliers and then with various categories of semiconductor products and techniques needed to make them.

\footnotetext{
${ }^{12}$ Directions in Engineering Research - An Assessment of Opportunities and Needs, p. 248 (Washington, DC: National Academy Press; 1987).

${ }^{13}$ Ibid., p. 182.
} 
Figure 1.

The contribution of semiconductors to the economy.

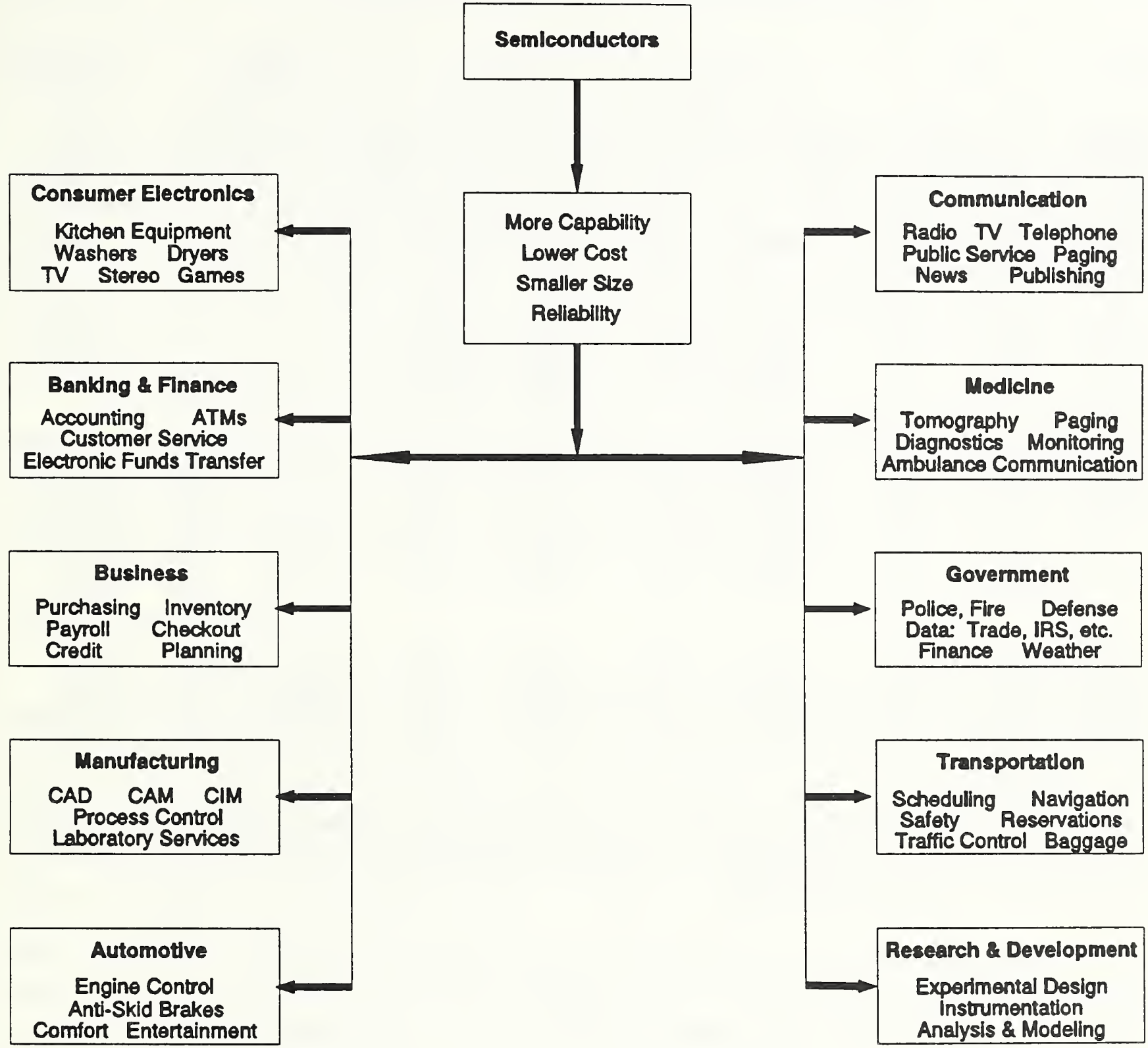

All of these industrial groups serve a world-wide market.

The sizes of the companies in these businesses vary widely. Semiconductor material, gas, and chemical suppliers tend to be divisions of large chemical companies. Some specialty gas and chemical suppliers are small, providing specially purified and packaged products solely for semiconductor manufacturing purposes. Manufacturing equipment makers are mostly small companies. There are a few medium-sized ones, most of which are mini-conglomerates formed by acquisition of small companies. The principal exceptions to the pattern are in Japan, where a small number of the large device makers (Hitachi, Toshiba, and NEC, primarily) either make semiconductor manufacturing equipment or have subsidiary companies that do. 
Table 3

Semiconductor Industry Production

\begin{tabular}{|c|c|c|c|c|c|c|c|c|c|}
\hline \multirow{3}{*}{ Year } & \multicolumn{9}{|c|}{ \$ millions ${ }^{1}$} \\
\hline & \multicolumn{2}{|c|}{ US } & \multicolumn{2}{|c|}{ Japan } & \multicolumn{2}{|c|}{ Europe } & \multicolumn{2}{|c|}{ ROW* } & Total \\
\hline & $\$$ & $\%$ & $\$$ & $\%$ & $\$$ & $\%$ & $\$$ & $\%$ & $\$$ \\
\hline 1952 & 19 & 100 & & & & & & & 19 \\
\hline 1955 & 40 & 100 & & & & & & & 40 \\
\hline 1960 & 594 & 97.2 & 8 & 1.3 & 9 & 1.5 & & & 611 \\
\hline 1965 & 1122 & 69.3 & 183 & 11.3 & 315 & 19.4 & & & 1620 \\
\hline 1970 & 2151 & 65.8 & 587 & 18.0 & 532 & 16.3 & & & 3270 \\
\hline 1975 & 3367 & 60.1 & 1081 & 19.3 & 1155 & 20.6 & & & 5603 \\
\hline 1980 & 9839 & 54.2 & 5359 & 29.5 & 2892 & 15.9 & 80 & 0.4 & 18170 \\
\hline 1985 & 16319 & 52.7 & 10862 & 35.1 & 3104 & 10.0 & 674 & 2.2 & 30959 \\
\hline 1986 & 17598 & 45.5 & 16546 & 42.8 & 3574 & 9.2 & 990 & 2.6 & 38708 \\
\hline 1987 & 2.1295 & 45.5 & 20021 & 42.8 & 4324 & 9.2 & 1198 & 2.6 & 46838 \\
\hline 1988 & 28110 & 43.4 & 28705 & 44.3 & 5178 & 8.0 & 2788 & 4.3 & 64781 \\
\hline 1989 & 29387 & 41.6 & 32558 & 46.1 & 5186 & 7.4 & 3459 & 4.9 & 70590 \\
\hline $1990 \mathrm{e}$ & 30271 & 43.1 & 31337 & 44.6 & 4799 & 6.8 & 3771 & 5.4 & 70178 \\
\hline 1991e & 29654 & 43.1 & 30545 & 44.4 & 4622 & 6.7 & 3937 & 5.7 & 68758 \\
\hline $1992 \mathrm{e}$ & 37153 & 41.6 & 40317 & 45.1 & 6211 & 7.0 & 5733 & 6.4 & 89414 \\
\hline
\end{tabular}

${ }^{*}$ ROW $=$ rest of world.

${ }^{1}$ Data for 1970 and later include both merchant and captive producers. Data for 1990 and beyond are estimated. Data before 1970 do not include captive producers, and are listed by nationality of the supplier, not region of production.

Source: VLSI Research, November 1990.

Companies that make semiconductor devices vary widely in character. Some (e.g., IBM, Delco, Digital Equipment) make devices entirely for their own internal purposes. These are "captive" semiconductor device makers. Others (e.g., AT\&T, Motorola, Texas Instruments, most Japanese firms, Siemens, Philips) make devices both for internal use and external sale. They are thus captive and merchant manufacturers at the same time. The remainder (e.g., Intel, National) are almost totally merchant device makers. This group also includes dozens of small companies, mostly in the U.S. Most U.S. semiconductor device makers are the product of the entrepreneurial approach that has flourished here but is quite exceptional elsewhere.

The abilities of these varying sizes of firms to compete in international markets differ markedly. The large firms may do as they choose with some success. Small ones often have great difficulty, though not necessarily. A small company with a strong proprietary product position, good management, and a conservative balance sheet can do well worldwide. 


\section{KEY TECHNOLOGIES}

\section{Materials}

\section{Silicon}

Two German firms (Wacker Chemitronic and Dynamit Nobel, now part of MEMC) produced over half of the world's silicon for most of the past 15 years but no longer do. Both companies have strong research activities that continue to provide steady advances. The Japanese have four large silicon producers each with good research operations. Collectively, they are now larger producers than the Germans. Other Japanese companies, notably Nippon Steel, have entered the silicon business in addition to the four referred to. Both the German suppliers and some of the Japanese ones have major facilities in the U.S. U.S.-owned producers account for less than five percent of the world's silicon production.

About 18,000 metric tons of raw, high-purity semiconductor silicon are produced each year. Losses during the process of making this material into polished wafers consumes about half. The remainder, mostly in the form of one-side-polished wafers about $0.7 \mathrm{~mm}$ thick and ranging in diameter from 100 to $200 \mathrm{~mm}$, is used to make devices. Wafer use is reported in area terms, and was 1940 million sq.in. (110 million wafers) in 1989.

\section{Compound semiconductors}

Only about 20 tons of GaAs, the principal compound semiconductor material, are produced annually. Sumitomo Electric makes about 60 percent and is a leader in R\&D for product improvement. The balance is made by numerous small firms that, in the U.S., tend to be owned by much larger companies. For GaAs substrate material, the U.S. is behind and holding its position in basic research and in development but not doing so well in production.

There are serious structural and purity problems in these materials. Source materials are often not available in the necessary purity. Crystals of compound materials are much more prone to breakage than is silicon; reduction of internal stresses is a necessity.

The U.S. is doing better in R\&D on compound materials having complex layered structures that are used to make semiconductor lasers and some specialized transistors. We are roughly even with Japan in basic research, although here the work is done largely in universities and by military contractors (major exceptions: Bell Labs and IBM), while in Japan the research is in industrial and government laboratories. They are thus in a better position to bring the fruits of the research to market for civil applications.

\section{Chemicals and gases}

Semiconductor production uses a wide range of chemicals and gases. Unfortunately, on the scale that most chemicals are produced, the quantities of any given chemical that are used are small. Thus the suppliers in the U.S. have tended not to put forth as much effort in producing chemicals of exceptional purity as the suppliers in Europe or Japan. Some chemicals and gases are difficult to ship internationally, so U.S. suppliers have been shielded from foreign competition to some extent. A recent change has been the purchase of several U.S. suppliers 
of gases and gas-handling equipment by European and Japanese companies, thus internationalizing the gas business by ownership.

\section{Plastic molding materials}

Plastic molding compounds are used in forming the body of finished semiconductor devices. The plastic enshrouds the silicon chip and can contaminate it if the molding compounds are not specially purified. As in the case of chemicals, U.S. suppliers have not pursued the semiconductor application with vigor. Most plastic molding materials now come from Japan.

\section{Photomasks and mask substrates}

Photomasks are made of glass or fused quartz plates (the substrate) on which the master patterns are created for making images on the silicon wafer that define the configuration of each layer in an integrated circuit. Photomask patterns must be perfect. The substrate must be quite flat. There can be no flaws on the surface or in the body of the substrate that would cause errors in the projected image on the wafer. By providing superior quality at lower prices, the Japanese have acquired almost the entire substrate business (Hoya) and a substantial part of the merchant photomask business (Dai-Nippon Printing). Roughly half of the photomasks used are made in-house by the device makers, but on purchased substrates.

\section{Manufacturing Issues}

\section{Manufacturing equipment}

The U.S. has led this $\$ 9.6$ billion industry from the start. It is under a strong challenge from Japan, which has risen in world market share from 24 percent in 1985 to 42 percent in 1989 , mostly at the expense of the U.S., whose market share fell from 61 to 48 percent in the same period. Japanese companies now make the best step-and-repeat patterning gear and the fastest final test equipment. ${ }^{14}$ Because much of the technology for semiconductor manufacturing is embodied in equipment, loss of leadership in this field would be very serious indeed. The U.S. industry now has less than half of the world market, and this share is steadily declining.

Europe has several small firms with products that sell competitively in the U.S., but overall they are not a major competitor. We lead in ion implantation and in some kinds of film deposition (silicon epitaxy, for example). The U.S. also leads in many areas of measurement instrumentation. Most firms are small, having less than $\$ 100$ million in annual sales. A protracted slump in semiconductor device demand in 1985-86 hit equipment manufacturers doubly hard, because device factories were overbuilt in 1984. This excess capacity meant equipment sales were very low for years. Exports to the PRC were the one bright spot for firms with equipment that could be licensed for shipment, but by no means all firms could take advantage of this opportunity.

\footnotetext{
${ }^{14}$ The VLSI Manufacturing Outlook, VLSI Research, Inc., San Jose, CA (1990).
} 
This picture is changing. Equipment previously in use is becoming obsolete (a five year life span is a long one in the semiconductor industry). Automation, regardless of the cost, is required to manufacture sub-micrometer geometries at acceptable yields. People shed too much dirt and must be excluded from clean factories. This equipment is remarkably sophisticated. It is built in clean rooms and designed to be used and maintained in clean rooms without emitting contaminant fumes or particles. Most of it is at least microprocessor controlled. It is also expensive. Single items costing over a million dollars are common. It now costs about $\$ 500$ million as a minimum to build and equip a semiconductor plant of economically viable scale. There are currently 1000 semiconductor plants in the free world, though only a few percent of these are of this modern expensive vintage.

Device design

This is the only area in which the U.S. leads everyone and is holding position. The most successful computer-aided design systems are U.S.-made. This is a software-intensive field. The major device and process modeling codes, used everywhere, originated at U.S. universities. Japanese device makers are becoming more proficient in modeling and design as they close the software gap.

\section{Process control}

The Japanese manufacturers excel at process control as the key ingredient in quality control. The overall result is the production of high quality, reliable products at high yield, i.e., low cost. Japan's effectiveness in the semiconductor business is directly traceable to this way of doing business. U.S. companies became lax about quality control during the 1970's, were abruptly awakened by the Japanese, and have been trying hard to re-establish parity. There has since been a great improvement in U.S. quality, but still not enough. European device makers have had a similar history. Siemens has teamed up with Toshiba and is absorbing the Japanese process and quality control ethic with very positive effects on yield.

\section{Process automation}

Automation of a semiconductor plant is expensive. Mitsubishi has two automated plants making memory chips and is building a third. Their yield has significantly improved (by 20 percent) because there are fewer operator errors and because there are fewer operators, the major source of contamination in semiconductor plants. The two existing plants, one built in 1983 and the other in 1985, can produce 18 million memory devices a month with 650 employees; the total capital cost was $\$ 455$ million, a substantial price for that time. There are several other fully automated Japanese plants, but few elsewhere in the world.

Some industry standards exist for the necessary communication between machines and host computers. Much manufacturing equipment is equipped to meet these standards either as a standard feature or as an option. Other standards, such as those for the physical locations of facilities connections, work surface height, points for supply and removal of work in process, and means for interfacing with mobile robots, are only beginning to be developed. No standards exist for integrating the information gathered from all sources (equipment, measurement tools, 
material flow data, environmental conditions, safety alarms, and the like) in a semiconductor plant. A few proprietary data management systems are available on the market. Few semiconductor firms are willing to accept these as offered, but have developed their own; none of these proprietary systems can be considered standard.

Once the various data communication systems are in place, one must deal with a flood of numbers that may be useful to machines and computers but which entirely overwhelms human beings. The conversion of data into information that can be understood by people and used to manage an automated factory is an additional very difficult step. Some type of machine learning system will be needed to search the streams of data for patterns that indicate when exceptional situations exist and suggest appropriate actions to deal with them.

\section{Devices}

The larger application areas for semiconductor devices are given in Table 4. The table shows North American consumption; for Japan and Europe the military segment is less and the consumer segment is larger, but the pattern is similar.

\section{Advanced microcircuits}

Table 5 shows the world market for the principal classes of semiconductor devices. The competitive circumstances surrounding each of the several types of advanced ICs are different. Four types, memories, microprocessors, custom logic circuits, and logic circuits made from compound semiconductor materials will be mentioned here. In recent times, U.S. R\&D for the most advanced circuits was done either as part of the DoD VHSIC ${ }^{15}$ program or in the larger commercial houses, many, like IBM, captive producers. The diffusion of technology from captive suppliers or VHSIC contractors into the merchant suppliers was slow, so we did not obtain maximum benefit from our expenditures. The establishment of SEMATECH is helping to improve the transfer of technology within the 14 member companies. Japanese R\&D is done by the large suppliers for both captive and commercial purposes, by government laboratories, by Nippon Telegraph and Telephone (which has a strong technology transfer activity to its suppliers), and by government-sponsored cooperative research programs in the industrial laboratories. Coupling to the commercial market is thus quite effective.

Japan chose to enter the memory business aggressively in the early 1970's to make these highly standardized circuits in large quantities. The development chronology is shown in Table 6. Its success was such that most U.S. suppliers left the field. Whether we can recapture this business is quite debatable. Some of the larger European firms are still making memories, but are not reported to be making money.

The U.S. has maintained a strong position in microprocessors, partly because we are still leading the world in software; the development of the software for a new microprocessor is at least as expensive as developing the chip. Once accepted in the market, microprocessors have a long life. Chip copyright laws have helped reduce the design copying that was a problem for a time. Until recently, Japanese firms have had to license the right to produce microprocessor

\footnotetext{
${ }^{15}$ VHSIC = Very High Speed Integrated Circuit
} 
Table 4

1990 North American Semiconductor Consumption Millions of dollars

$\underline{\text { Segment }}$

Data Processing

Computer

Data storage

Data terminals

Input/output

Dedicated systems

Subtotal

Communications

Customer premises

Public telecom

Radio

Broadcast \& studio

Other

Subtotal

Industrial

Security, energy

management

Manufacturing sys.

Instrumentation

Medical equipment
Value CAGR*

$\$ 4749$

1373

215

455

175

$\$ 6968$

$\$ 1271$

437

528

156

112

$13.1 \%$

16.9

7.0

8.3

3.2

$12.9 \%$

$\$ 2504$

$13.1 \%$

10.8

18.4

14.4

13.8

$13.8 \%$

$\$ 176$

1057

$12.2 \%$

12.1

502

457
Transportation

TOTAL

$\underline{\text { Segment }}$

Comm'l. aviation

Other

Subtotal

Consumer

Audio

Video

Personal electronics

Appliances

Other

Subtotal

Military

$\$ 2176$

$\$ 1319 \quad 10.8 \%$

$\$ 16812 \quad 11.7 \%$

designs from the original producer, but indigenous designs are beginning to have some success. The U.S. will continue to lead for a few years, but after that the future is uncertain.

Custom circuits take many forms. They are used in growing numbers (see Table 7) in applications for which very few of a given kind of device will ever be needed, such as shortproduction-run instruments, or in applications in which very large numbers of identical circuits are required, such as cars or television sets. This only appears to be a contradictory statement. In the first example, the cost and size of an instrument can be reduced by using an easily customized gate array. The simplest ones are derived from standard designs of individual logic elements (gates) with final metallization patterns to connect the gates into circuits for special purposes. This is an economical approach for small quantity requirements. Others examples are microprocessors that have been customized by providing them with fixed, pre-programmed memory that dedicates the microprocessor to a single application. This approach is used for applications requiring functions too costly when inplemented by the standard cell approach. Still other types are designed from scratch for specific purposes. This is costly, so it is reserved for 
Table 5

World Market for Various Types of Semiconductor Devices

(Millions of Dollars)

Type

Bipolar digital

$\underline{1980}$

Memory

Logic

MOS digital

Memory

Microprocessors

Logic

2374

572

1802

4715

2230

862

1623

Analog

2457

Total IC

Total Discrete

Total Optoelectronic

$\underline{9546}$

$\underline{3883}$

Total Semiconductor ${ }^{1}$

$\underline{689}$

14118

$\begin{array}{r}\frac{1985}{3672} \\ 589 \\ 3083 \\ 10122 \\ 3821 \\ 2748 \\ 3553 \\ 4761 \\ \underline{18555} \\ \underline{4576} \\ \underline{1226} \\ \hline\end{array}$

$\underline{1990}$

$\underline{1994}$

4577

421

497

4156

1999

4185

239

3946

${ }^{1}$ Source: Dataquest. Data include intracompany consumption for merchant suppliers and exclude consumption by full captives.

Table 6

Dynamic Random-Access Memory Chronology

\begin{tabular}{|c|c|c|c|c|c|c|}
\hline Size & \multicolumn{2}{|c|}{$\mathrm{CD}^{*}, \mu \mathrm{m}$} & First Paper & $1 \mathrm{M} / \mathrm{yr}$. & \multicolumn{2}{|c|}{$100 \mathrm{M} / \mathrm{yr}$. } \\
\hline $16 \mathrm{~K}$ & 3.6 & 1976 & Intel & 1977 & 1980 & Intel \\
\hline $64 \mathrm{~K}$ & 2.5 & 1978 & NTT & 1980 & 1983 & Fujitsu \\
\hline $256 \mathrm{~K}$ & 1.5 & 1980 & NEC, Toshiba & 1983 & 1986 & Hitachi \\
\hline $1 \mathrm{M}$ & 1.0 & 1984 & NEC, NTT & 1985 & 1988 & Toshiba \\
\hline $4 \mathrm{M}$ & 0.8 & 1986 & TI & 1988 & 1991 & Hitachi \\
\hline $16 \mathrm{M}$ & 0.6 & 1988 & $\begin{array}{l}\text { Toshiba, Hitachi } \\
\text { \& Matsushita }\end{array}$ & 1991 & 1994 & \\
\hline $64 \mathrm{M}$ & 0.4 & 1991 & $\begin{array}{l}\text { Toshiba, Matsushita } \\
\text { Mitsubishi \& Fujitsu }\end{array}$ & 1994 & 1997 & \\
\hline $256 \mathrm{M}$ & 0.3 & 1994 & & 1997 & 2000 & \\
\hline $1024 \mathrm{M}$ & 0.2 & 1997 & & 2000 & 2003 & \\
\hline
\end{tabular}

${ }^{*} \mathrm{CD}=$ critical dimension

Source: P.K. Chatterjee in Electronic Engineering Times, 1/29/90, and G.B. Larrabee, both of Texas Instruments.

cases (the second example above) in which large numbers of identical parts will be needed. 
Until recently, the U.S. had a strong position in custom circuits. Now the Japanese are as competitive in custom circuits as we are.

\section{Table 7 \\ Estimated Worldwide ASIC* Consumption \\ (Millions of Dollars)}

$\begin{array}{lrrrrr} & \underline{1986} & \underline{1988} & \underline{1990} & \underline{1992} & \text { CAGR** } \\ \text { Gate Arrays } & \$ 1798 & \$ 3164 & \$ 4851 & \$ 7832 & 26.6 \% \\ \text { Programmable Logic } & 308 & 583 & 918 & 1161 & 22.7 \% \\ \text { Total semicustom } & \$ 2106 & \$ 3747 & \$ 5769 & \$ 8993 & 26.1 \% \\ \text { Cell-Based ICs } & \$ 674 & \$ 1263 & \$ 2091 & \$ 3611 & 31.5 \% \\ \text { Full-Custom ICs } & 2160 & 2395 & 2148 & 2088 & (1.8) \% \\ \text { Total ASIC } & \$ 4941 & \$ 7404 & \$ 10008 & \$ 14692 & 19.5 \%\end{array}$

*ASIC $=$ application-specific integrated circuit

**CAGR = compound annual growth rate 1987-92.

Source: Dataquest, June 1987

Logic devices using compound semiconductors are only beginning to appear in useful quantities. The growing availability of these devices is shown in Table 8. They are faster than silicon chips but much more expensive, so they are attractive only for supercomputers and for military purposes requiring the highest computational speeds. The technology required to make them is useful in making advanced optoelectronic devices and will be used for optical computing chips in the future, if present expectations come true. The present level of integration is much lower than for advanced silicon chips, in part because of the problems with the materials mentioned earlier. Again, work done by U.S. DoD contractors is not well coupled into commercial firms.

\section{Optoelectronics}

Optoelectronic devices are made from compound materials and include light-emitting diodes (LEDs), semiconductor lasers, and some photodetectors. The most demanding applications are in optical communication systems, but enormous numbers of LED's are made for indicating lamp applications. All uses of compound materials, including the logic circuits mentioned above, account for about five percent of the dollar volume in semiconductor devices but use only 0.1 percent as much material in weight terms as is used for silicon devices. Compound semiconductor materials are intrinsically expensive and difficult to process, and thus are only used when there is no alternative.

Much U.S. research is done in universities, and done well. In Japan, the research outside of company laboratories is done by government laboratories and consortia. On balance, we are ahead in research and they are ahead in implementation. This area of semiconductor technology 
Table 8

Worldwide GaAs Semiconductor Merchant Consumption
(Millions of Dollars)

$\begin{array}{lrrrrr} & \underline{1986} & \underline{1988} & \underline{1990} & \underline{1992} & \underline{\text { CAGR* }} \\ \text { Analog/Linear ICs } & \$ 107 & \$ 177 & \$ 294 & \$ 532 & 15.7 \% \\ \text { Digital ICs } & 51 & 96 & 208 & 577 & 52.0 \\ \text { Optoelectronics } & 1586 & 2088 & 2378 & 3168 & 12.0 \\ \quad \text { Discretes** } & 1558 & 2021 & 2216 & 2915 & 10.7 \\ \quad \text { ICs } & 28 & 67 & 162 & 253 & 42.5 \\ \text { Microwave discrete } & 203 & 244 & 288 & 345 & 9.2 \\ \text { Total } & \$ 1947 & \$ 2605 & \$ 3168 & \$ 4622 & 15.7 \%\end{array}$

${ }^{*}$ CAGR $=$ compound annual growth rate 1986-92.

**Discrete devices are mainly light-emitting diodes and lasers.

Source: Dataquest, March 1989. Data include intracompany consumption for merchant suppliers and exclude consumption by full captives.

is only just beginning to show its potential. Optical communication is growing rapidly. Faster computers are always sought. Optical computation is a tempting objective, though it will be realized only at some time in the future.

\section{Microwave ICs}

These special-purpose circuits are used for satellite communication, military systems, and an increasing number of civil applications at frequencies from 1 to $100 \mathrm{GHz}$. Europe, Japan, and the U.S. are developing these for telecommunication applications. We and the Europeans also have military interests. In Europe and Japan the civil applications under development include direct TV broadcast from satellites to homes and vehicle detection and communication systems to control traffic, give routing information to vehicles, and warn drivers of impending collisions.

The distinguishing feature of these circuits is that their interconnections are specially designed for good high-frequency properties, which requires that the area taken by interconnections be large. The approach provides uniform, designable circuits having wide frequency response and relatively small size and weight. The high operating frequency leads to special problems. Unique design software is required. Chip testing is difficult; conventional methods cannot be used. Data transfer rates are rising for conventional ICs; $100 \mathrm{MHz}$ clock frequencies are used in the latest microprocessors. Package and internal conductor design for "ordinary" ICs will soon have to be done using microwave approaches. More information on microwave ICs may be found in the microwaves chapter. 


\section{Power devices}

High power semiconductors for power-frequency applications up to $400 \mathrm{~Hz}$ are used in power supplies, some very large (e.g., $1200 \mathrm{~V}$ at 250,000 A). Due mainly to underinvestment in R\&D and in modern facilities by U.S. companies and the existence of large electric railway systems (major customers) in Europe and Japan, we are behind and losing ground. This market is not likely to be recovered. Other devices, used in switching power supplies, high power audio, and radio frequency amplifiers, are still technically viable in the U.S.; here we are about even and will probably remain so for some time.

\section{TRENDS IN THE TECHNOLOGY}

The dominant trend in semiconductor technology is toward more complex integrated circuits, for the purpose of supplying more useful functions and reduced cost to the user. This has been the direction of the industry for 25 years. No change is in sight for at least the next decade. All other trends are consequences of this single one. Table 9 illustrates some of these consequences. But these consequential trends involve major technological achievements on a wide front. For this reason, the 40-year-old semiconductor industry and its suppliers are still riding (creating?) a wave of "emerging technology."

Attributes of materials have always defined the limits of semiconductor technology. The need for high purity has been mentioned before. Device makers have continually pressed materials suppliers for improved purity levels, to an extent that at times seems to be an article of faith rather than supported by hard information. (Getting such information is expensive and time-consuming.) Part of the reason for this is the difficulty of measuring purity at the levels the device makers desire. Another reason is that in the past there have been episodes of catastrophic device yield loss that have been traced to impure materials. The device makers, once burned, are twice shy.

A significant change is beginning to occur in the way materials are specified. In the past, a given property of a material was required to have a value between an upper and a lower bound. For example, a metal rod might be specified to have a minimum diameter of $0.248 \mathrm{in}$. and a maximum diameter of $0.252 \mathrm{in.}$. Any value meeting these conditions was acceptable, and other values were not. The implicit but seldom stated assumptions involved in this kind of specification are first, that any value that was acceptable was as suitable for the application as any other, and second, that measurements could cleanly distinguish whether or not the material met the specification. For many semiconductor applications, neither one of these assumptions is true. There is often a preferred or "target" value for the property. Further, as the specified range of values of a property becomes squeezed ever smaller, the uncertainties in measurement often are about the same as the range itself. It is thus not possible to tell if the specification has been met or not.

Now, rather than guaranteeing that an attribute will always meet a given condition (requiring the materials supplier to be very conservative in specifying his product), a target value is set based on the user's requirements. Both supplier and user of the material understand that at times this value will not be met, so statistical limits are negotiated on the frequency and degree of deviations that may occur because of variations in the supplier's process and in both 
Table 9

IC Manufacturing Trends

$\begin{array}{llllll}\text { Date of first functional device }^{1} & 1987 & 1991 & 1994 & 1997 & \\ \text { 1M units manufactured } & 1988 & 1994 & 1997 & 2001 & \\ \text { DRAM size } & 4 \mathrm{M} & 64 \mathrm{M} & 256 \mathrm{M} & 1024 \mathrm{M} & \text { bits } \\ \text { Minimum line width } & 0.8 & 0.4 & 0.3 & 0.2 & \mu \mathrm{m} \\ \quad \text { registration tolerance } & \pm 0.2 & \pm 0.1 & \pm 0.08 & \pm 0.05 & \mu \mathrm{m} \\ \text { line width tolerance } & \pm 0.1 & \pm 0.05 & \pm 0.04 & \pm 0.02 & \mu \mathrm{m} \\ \text { killer defect size } & 0.15 & 0.08 & 0.06 & 0.04 & \mu \mathrm{m} \\ \text { Chip size } & 90 & 200 & 300 & 450 & \mathrm{~mm}^{2} \\ \text { Wafer diameter* } & 150(1991) & 200(1997) & 250(2000) & 300(2005) & \mathrm{mm} \\ \text { Lithography field size } & 15 \times 15 & 20 \times 20 & 25 \times 25 & 30 \times 30 & \mathrm{~mm} \\ \text { Number of mask levels, average } & 18 & 24 & 28 & 32 & \\ \text { Single wafer processing } & 40 & 60 & 80 & 100 & \% \\ \text { Liquid processes } & 35 & 25 & 15 & 0 & \% \\ \text { Gaseous processes } & 65 & 75 & 85 & 100 & \% \\ \text { Wafer factory capital cost } & \$ 250 \mathrm{M} & \$ 500 \mathrm{M} & >\$ 1 \mathrm{~B} & >\$ 1.5 \mathrm{~B} & \\ \text { Factory automation } & 30 & 60 & 90 & 100 & \% \\ \text { Equipment cost (relative) } & 1 \times & 1.5 \times & 2 \times & 2.5 \times & \\ \text { Throughput, wafers/month } & 25 \mathrm{~K} & 20 \mathrm{~K} & 20 \mathrm{~K} & 15 \mathrm{~K} & \\ \text { Processed wafer direct cost } & \$ 250 & \$ 500 & \$ 800 & \$ 1250 & \text { each } \\ \text { Processed wafer cost }{ }^{2} & \$ 417 & \$ 917 & \$ 1633 & \$ 2917 & \text { each } \\ \text { Chips per production wafer* } & 184 & 146 & 152 & 146 & \text { units }\end{array}$

${ }^{1}$ As reported at the International Solid State Circuits Conference.

${ }^{2}$ Includes depreciation of factory capital cost assuming 5-year straight-line depreciation.

"at a production rate of $100 \mathrm{M}$ units/year.

Source: Technology Trends Assessment, SRC Summer Study, Wild Dunes, SC, Sept. 6-8, 1989; further data from G.B. Larrabee, Texas Instruments.

parties' measurement capabilities. There must be a closer relation between the two parties for this approach to work. In its optimal form, this relationship is collegial and mutually supportive in addressing problems, rather than the traditional adversarial one. This approach is new in U.S. practice, but derives directly from Japanese practice. The originator of the idea is $\mathrm{W}$. Edwards Deming, but the implementation is due to Prof. Genichi Taguchi.

A similar approach to cooperative development and improvement of manufacturing equipment is also developing. There have been examples of this in the past, but now cooperation is becoming the norm. SEMATECH started to pursue this path vigorously in 1990 . The funding of development programs is shared between SEMATECH and the equipment firm under the condition that the new tool will be first available exclusively to SEMATECH and its member companies. When these needs have been met, the supplier is free to sell to anyone. In addition, SEMATECH is trying valiantly to change the frequently adversarial relationship between suppliers and their customers into a cooperative one, to reflect more constructively the real 
interdependence between them. If this effort succeeds, it will be a major contribution to improving U.S. competitiveness in the semiconductor field.

The entire approach to manufacturing semiconductors is changing in directions that rely increasingly on more and better measurements and a stronger base of fundamental knowledge of each process. ${ }^{16}$ Table 10 illustrates this evolution from empirically-based, manual operations to knowledge-based automated operation.

Table 10

The Move Toward Intelligent Microelectronics Manufacturing

1970-1980's

Empirically developed and

"force-fit" into commercial

equipment

Batch processing generically developed for broad families of processes

1950's "Western Electric" rules. Control based on measurements on pilot wafers.

Control to specification limits.

All measurements on offline equipment

Sensors

Data gathering and lot manual planning at fixed times
Mid to Late 1990's

Chemical models, developed

Processes in concert with the equipment

developed in concert with each process

Adaptive, robust, with artificial Process Control intelligence (AI). Based on thermodynamic-kinetic models. Control to target value.

Smart microsensors, with computing at the sensor

Recipe downloading, AI tracking, Factory Control intensive, real time process control

Source: Graydon B. Larrabee, Texas Instruments

Concerns about the cost of equipment, its rapid obsolescence rate, and the difficulties of contamination control have led to a concept of modular equipment ("cluster tools") that is being seriously pursued. The concept involves a number of tools that perform a sequence of different processes "clustered" about a core module. The core provides material handling in a clean vacuum environment and is the communications link between the tools surrounding it and the computers that manage materials flow and the processes executed by the entire cluster of equipment. The expectation is that the functions of the central core will be relatively invariant over time and will need replacement only rarely. If a process tool becomes outdated, it can be

\footnotetext{
${ }^{16}$ SEMATECH is now devoting about half of its expenditures on external contracts, concentrated on four "major thrust" areas - lithography, metrology, multilevel metallization, and manufacturing methods and processes. See SEMATECH 1990, a report to Congress by the Advisory Council on Federal Participation in SEMATECH, May, 1990, p. ES-4.
} 
replaced if there is a standard interface between the core and the tool. The first industry standard for this interface has just been established.

The shrinking scale of features on the chip leads directly to tighter limits on processes. Film thicknesses and properties must be more closely controlled. The absolute uncertainty must decrease in proportion to thickness to maintain at least the same percentage of uncertainty. In addition, as the entire sequence of manufacturing processes acquires more steps, the variations in each step must be decreased to maintain control over the whole.

Today's processing equipment makes a few in-line measurements of its own performance, such as detecting the end point of an etching process ${ }^{17}$. Most such control is still rather rudimentary. Film deposition and removal processes involve chemical and physical phenomena that are generally not well understood in detail. Control tends to be of the "black box" type, in which it is assumed that if flow rates, temperatures, and similar input conditions are maintained then the product of the process will not vary. The process itself is the black box, about which little is known. This approach does not work well for many reasons. Not every condition that affects the process is measured and controlled. For example, keeping a uniform flow rate of an input gas stream does not help if the composition of the gas is not also well-controlled. Many chemical reactions are strongly influenced by small changes in the level of trace impurities. Thus, the performance of equipment can vary with the time since it was last cleaned. Small changes in the impurity level of input gases can also have disproportionate effects.

Successful automation of the entire fabrication process requires detailed, accurate information concerning the execution of every process step. See Table 11 for the amount of data involved. For some process steps this can be approached, but others change the silicon wafer in ways that are not immediately measurable. Information about such steps comes later, if at all, and corrective information must be fed back up the line of processes. Most processes result in an irreversible change to the wafer, so if there is an error in processing only two alternatives exist. Either the wafer must be scrapped, or (in only some cases) a change in a later process can have at least a partially corrective effect. In the latter case, correction information must be sent ahead of the wafer. Obviously it is much preferable to have information on process execution available immediately, so measurements made on the process line are more useful than those that require laboratory services and thus do not deliver information right away.

From time to time, a given process reaches some limit beyond which it cannot be pressed. Over the past decade, as device feature sizes have dropped, the end of optical imaging has repeatedly been foreseen. So far, ways have been found to meet the challenges and optical imaging is still the mainstay of the industry. It appears certain that optical techniques will serve at least to dimensions of $0.35 \mu \mathrm{m}$ and perhaps to $0.25 \mu \mathrm{m}^{18}$. Present state-of-the-art production devices are being made at $0.8 \mu \mathrm{m}$. Achieving good imagery at $0.25 \mu \mathrm{m}$ requires the use of very

\footnotetext{
${ }^{17}$ More such measurements are commonly made in Japan than in the U.S. (Private communication, G. Dan Hutcheson, VLSI Research.

${ }^{18}$ Successful engineering development of $0.3-\mu \mathrm{m}$ imagery using standard mercury i-line lithography tools in connection with phase-shift masks was reported at the 1990 International Electron Devices Meeting (San Francisco, December 1990) by more than one Japanese company. Some speakers projected that $0.15-\mu \mathrm{m}$ dimensions will be possible using optical means.
} 


\section{Table 11 \\ Information Quantity Trends}

LSI

Products (DRAM)

Thruput, wafers/month

Total process steps per lot

Number of types of equipment

Total equipment count

Number of process conditions

Database records/lot for stable production

Database records/month
$16 \mathrm{~K}$

10,000

100

40

70

200

100

$4 \times 10^{4}$
VLSI

ULSI
$4 \mathrm{M}$

50,000

550

120

400

1500

Source: K. Sato, Toshiba; quoted in Technology Trends Assessment, James F. Freedman, ed., SRC Summer Study, Wild Dunes, SC, Sept. 6-8, 1989, p. 93.

short wavelength ultraviolet light. ${ }^{19}$ If the wavelength is reduced beyond that point, the materials used for making lenses become opaque. This physical reason makes the argument for reaching the end of the optical road more convincing than it has been in the past. Before the end of the decade a new imaging method must be ready.

The choices are to use either electron beams or $\mathrm{x}$-rays. Electron beam equipment is now universally used to make the master patterns on photomasks. A fourth generation of equipment is under development, so the capabilities and limitations of the method are well known. Electron beams can write patterns at least as small as $0.1 \mu \mathrm{m}$ with excellent quality. The process is too slow, however, because each point in every pattern must be written one at a time. Exposure of a $150-\mathrm{mm}$ wafer takes 20 minutes or more, depending on the complexity of the pattern. Optical equipment now in use takes less than two minutes without regard to pattern complexity, because the image of the whole chip is exposed at one time.

$\mathrm{X}$-ray processes are more like optical ones. Entire patterns are exposed at one time, through a mask. But the technology is far less well developed than electron beam methods. Suitable x-ray sources are largely still laboratory instruments, not production tools. Most suffer from low intensity, except for synchrotrons. These machines were originally developed for nuclear physics research. Such machines are large and expensive. Smaller models are being developed for patterning wafers, but they will still cost upwards of $\$ 25$ million each without the wafer positioning equipment. X-rays have been used in the laboratory to make very attractive patterns, so in principle the method will work. But serious problems must be overcome in developing $\mathrm{x}$-ray sources, masks, resists, and wafer positioning equipment. The latter must be much more precise than that now used for optical imaging purposes. For use with a synchro-

\footnotetext{
${ }^{19}$ Basic physical principles state that the minimum feature size in an optical image cannot be smaller than the wavelength of the light used to produce it. Practical reasons limit resolution of lenses to a performance level somewhat poorer than this limit.
} 
tron, the wafer must be held in a vertical plane rather than horizontally, which introduces mechanical complexities. How this matter will be resolved is not yet clear.

Until a few years ago, film removal was typically done by wet chemical etching. This method is simple and inexpensive, but has the problem that the etching process proceeds laterally in the film as fast as it does vertically, producing edges of holes in the film that slope at about 45 degrees. If the film is much thinner than the smallest feature in the pattern one is trying to make, this is not a serious problem. But for most films, the film is now thicker than the smallest feature and wet chemical etching cannot be used. The lateral etching, coming from both sides of a small feature, leaves only a vestige of the original film. (The films are somewhat thinner than before, but the features are much smaller.) A new method was developed using gaseous etching in a partial vacuum. The gases are activated by an electrical discharge, which makes them more chemically active and also gives the gas molecules an electric charge. By applying an electric field, the gas molecules are directed more or less vertically against the horizontal wafer surface, allowing etching to proceed faster in the vertical direction than in the lateral direction. This produces film edges that are nearly vertical, which is the desired result. This process is called plasma etching, because the electrically activated gas atmosphere is a "plasma". Balancing these advantages is the fact that the bombardment of the silicon wafer by the high-velocity gas molecules can cause structural damage to the surface layers. This damage, if not avoided or later removed by a suitable heat treatment, adversely affects the electrical properties of the devices being made. Detection and measurement of this damage is a difficult and incompletely-solved problem.

Plasma processes can be used to deposit films as well, but for a different reason. Films can be deposited by chemical reactions in a furnace, or they can be grown by exposing the silicon wafer to oxygen in a furnace, forming silicon dioxide. Other processes also require heating the wafer. Whenever the wafer is heated, atoms in the silicon or in the films move around by diffusion, attempting to redistribute themselves uniformly rather than staying where the device designer intended they should be. As devices become smaller, the total time at high temperature experienced by a wafer must be strictly limited. Alternative ways to accomplish the purpose must be found. In plasma processes the energy required to stimulate the desired chemical process is provided by the electrical activation of the gas, rather than by the heat of a furnace. Plasma deposition processes are widely used, but are well-known generators of particles that can fall on the wafer surface. Ways to avoid this problem are being sought. Other means of adding energy to cause chemical reactions to proceed include the use of ultraviolet light or radiation from lasers. These methods are not yet in use but are being studied.

Particulate contamination during the manufacturing process has always presented problems. Smaller feature sizes mean that smaller particles, if they should fall on a wafer, can make a chip defective. Particles of concern are those of a size greater than roughly a fifth of the smallest feature dimension. To make circuits having $0.25 \mu \mathrm{m}$ feature sizes, particles larger than 0.06 $\mu \mathrm{m}$ must be excluded. Particles can fall out of the air, settle from liquids, or come from wearing moving parts of equipment. Some processes themselves generate particles by such means as nucleation and condensation from the gas phase in plasma and chemical vapor deposition equipment. Rough wafer handling can cause the edges to chip, generating silicon particles. People shed particles. Removal of all particles is not possible. Filters can remove 
them down to some critical size, but are less effective below that size $e^{20}$. The limit for filters in the room air supply is now about $0.1 \mu \mathrm{m}$.

Even detecting and counting very small particles is difficult. The usual method for counting particles in a gas or liquid stream uses an intense light, often a laser, shining across and through the stream. The light scattered from particles is detected. Larger particles scatter more light than smaller ones, so it is possible to determine the size distribution as well as to count them. But when the particles are of the same dimensions as the wavelength of the light (about $0.5 \mu \mathrm{m}$ ), individual particles do not scatter light in this way. Finding particles on a surface, such as that of a wafer, uses similar approaches and suffers from the same limitations.

Particles are not the only kind of contamination to be avoided. Dissolved impurities in liquids can leave residues on surfaces. Process materials themselves, if not properly removed, are contaminants in later steps. Photoresist is a good example.

New difficulties exist within the integrated circuits themselves as the dimensions become smaller. The electrical connections on the surface of the chip are very thin and narrow. While they carry only small electrical currents, the small cross-sectional area of these conductors is such that the density of the current is extremely high: approaching a million amperes per square centimeter, more than 1000 times that in ordinary house wiring. The stream of electrons, which is the electric current, can actually move the atoms of the conductor. Over time, this rearrangement of material (electromigration) may cause voids to develop in the conductor, further reducing the current-carrying capacity. Eventually the conductor melts and the circuit fails. The insulating layers of the chip, which separate electrically conducting regions and avoid short circuits, are highly stressed. These can fail with the passage of time. As the volume of individual parts of the circuit becomes smaller, previously insignificant effects of the boundaries of the part become more noticeable because the ratio of the surface area to the volume increases. These issues require research into causes of failures and ways to prevent them, and into the details of operation of extremely small transistors so that integrated circuit designers can cope successfully with these difficulties.

Additional trends also exist:

Increasing wafer size, increasing the need for uniform process control over larger areas. Automated wafer handling, because of greater wafer weight and the need to reduce particulate contamination and wafer damage.

Single wafer processing, to reduce the size and control the operating cost of equipment and increase the uniformity of processing. (Most present-day equipment processes many wafers at once.)

Statistical process control is becoming more prevalent.

Greater application of computers at all levels, for data communication and processing, adaptive process control, faster information feedback (thus quicker process correction). The data come primarily from metrology tools.

\footnotetext{
${ }^{20}$ Filters do not remove all particles larger than the specified size, nor do they pass all particles smaller than that size. Because unfiltered air contains very many more small particles than large ones, so does the filtered air even though the filters remove a large fraction of the particles smaller than the specified size.
} 
More in-process measurement. For example, Japanese experience ${ }^{21}$ shows that adding five percent to the cost of equipment for in-line sensors and data links results in:

$42 \%$ reduction in cycle time

$50 \%$ increase in output

$32 \%$ increase in equipment uptime

$25 \%$ reduction in direct labor hours.

Optimal use of these measurements also requires that process monitoring data, lot history data, and device functional test data be readily available for diagnostic work to guide corrective actions. Machine learning (or "artificial intelligence") tools can help greatly in identifying data patterns that characterize problems and also indicate paths to solve them.

\section{U.S. INDUSTRY GOALS}

The primary goal of U.S. manufacturers of materials, equipment, and semiconductor devices is to improve their competitive position while still making money. Their competitive position has been steadily eroding, as reflected in the share of the world market now held by U.S. companies in these industry segments. Many causes for this loss have been cited. In materials and devices, there was a period of U.S. insensitivity to the achievements of the Japanese in improving quality (which directly improves manufacturing cost). This was brought forcefully to national attention in 1980 by Hewlett-Packard's description ${ }^{22}$ of its experience with various suppliers of memory ICs. The defect rates at incoming inspection were dramatically better for products from Japanese suppliers than from U.S. suppliers. The latter have now improved their quality significantly. Some are fully competitive in this respect now.

U.S. silicon suppliers, in common with their competitors, have suffered from persistently low market prices, in part caused by industry overcapacity. The U.S. suppliers cut their R\&D efforts to reduce costs, but the German and Japanese firms did not. They thus learned from their development work how to reduce costs by improving efficiency. Ultimately the U.S. operations were sold to the foreign firms, and now industry rumors state that these U.S. operations with foreign owners are profitable. Companies must be willing to take a long-term approach to compete effectively with either European or Japanese firms, but that is not a popular approach with investors in this country.

The equipment makers, as a group, have kept doing their R\&D to the extent that small firms can, and have lost market share only with a fight. The competitive advantage in this field comes to equipment suppliers that are part of, or subsidiaries of, large companies. Those are mostly Japanese. In addition, there is a strong tendency for the Japanese device makers to buy from indigenous suppliers. Customer support is better from local suppliers anywhere. U.S. firms with strong support operations in Japan have generally done well. A few U.S. firms manufacture in Japan for the Asian market and find this presence to be a considerable advantage.

\footnotetext{
${ }^{21}$ DARPA JTECH panel report on computer integrated manufacturing and computer aided design for the semiconductor industry in Japan.

${ }^{22}$ R.W. Anderson at a seminar sponsored by the Electronics Industry Association of Japan, March 25, 1980, in Washington, DC.
} 
Given equal levels of technology in equipment, the firm supplying the better customer service has the advantage.

These three examples illustrate that what happens in the marketplace hinges on improved service to the customer. The technological factors that allow a company to perform better in the market need closer examination. Improved quality and reliability, better-functioning products, more repeatable operation, and lower costs come from purer and more uniform materials, closer control of processes, process and equipment improvements, better design techniques, and more effective ways of handling information.

\section{MEASUREMENTS TO MEET THESE GOALS}

New or better measurements are implicit in all of these approaches to improvement in service and competitiveness. That is an obvious need for providing purer and more uniform (better controlled) materials and for closer control of processes. One cannot control what one cannot measure.

In improving processes, equipment, designs, and information handling, the role of measurements is more subtle but equally important. Many processes are imperfectly understood. Their execution, and the design and operation of the equipment that performs the processes, are often based on empirical information, lacking anything better. Gaining an improved understanding of processes involves measuring what is occurring inside the process, learning about the physics and chemistry that govern the process, and obtaining quantitative, detailed knowledge of why the process works, what limits its performance, what to change to make improvements, and what to monitor to be sure the process is running right. These measurements and their interpretation are often difficult, but the research only needs to be done once. The results immediately translate into better control, more efficient processes, and the engineering data needed to design improved equipment. Numerous SEMATECH and $\mathrm{SRC}^{23}$ workshops and symposia sponsored by SEMI, ${ }^{24}$ ASTM,${ }^{25}$ NIST, and others have identified the need for this kind of information.

Quality improvement results from proper application of the information gained by improved measurements. First, all sources of variation (in materials, processes, tools, measurements) are eliminated or reduced as far as possible. Then design alternatives are chosen to make the processes and products as insensitive to residual variations as possible. Both of these steps involve carefully planned, statistically analyzed experiments. The end result is then the starting point for repeating the whole procedure. One never stops doing this, because new knowledge, tools, and experience become available to refine the manufacturing process still further.

\footnotetext{
${ }^{23}$ The Semiconductor Research Corporation is a consortium funded by 31 member companies and six government agencies to fund university research on semiconductor-related subjects. It funds about $\$ 30$ million in research (including about $\$ 10$ million from SEMATECH) at nearly 50 universities.

${ }^{24}$ SEMI = Semiconductor Equipment and Materials International, an international industry association of suppliers to the semiconductor device makers, and a large international standards organization.

${ }^{25}$ Formerly the American Society for Testing and Materials, now simply named ASTM; the largest private-sector standards-producing organization in the U.S. Its Committee F-1 on Electronics is the primary producer of measurement standards for semiconductor materials and processes in the world.
} 
The design of integrated circuits is based on detailed knowledge of the operation of the individual transistors that comprise the circuit. Whenever the scale of dimensions of the circuit is changed, the behavior of the transistors changes, often in ways that were not foreseen. Computer models of devices are widely used to predict the performance of these circuit elements, based on the physics of transistors and solid state materials. Certain physical assumptions are built into all computer models, and as devices are scaled down these assumptions may no longer be correct. This leads to errors in the predictions of the model. Corrections of these problems involves searching out the causes, improving those parts of the computer model, and verifying the changes by measurement of transistors specially made to provide the data to show that the problem has been solved. Again, such work only needs to be done correctly once to be of benefit to the entire industry.

The example given above requires long-term research to deal with a problem. Many other measurement developments need substantial effort over a long time to create a generic solution. Few companies are willing to address such problems except to the limited extent necessary to deal with them as near-term obstacles. If the problem arises again during the development of the next generation of devices, it must be dealt with a second time. Device companies are not usually in the business of creating complete solutions to measurement problems. Such work is a diversion from product development. Similarly, universities do not often solve measurement problems well. The time required is longer than the typical tenure of a graduate student. Only a few laboratories, such as NIST and some of its counterparts in other countries, have a mission to do this kind of work.

Information handling is central to management of semiconductor manufacturing at every level. Engineers need detailed technical data to detect or anticipate problems. Equipment gathers data on its operations and its condition. Instruments evaluate the results of manufacturing processes. All of these data come from measurements of some kind. One prefers that the measurements be done correctly and the data be significant. But the best measurements are of no value unless the results are communicated to those who need them. This does not occur as simply as it might, and sometimes not at all. Many kinds of computers are involved, speaking different languages. Some are on differing types of networks that cannot work together. These communication problems need solution.

Even so, a torrent of data assaults the process engineer, most of it reporting that everything is under control and thus needing no action. Computer tools to sift out the data patterns that indicate trouble are badly needed, and are just beginning to emerge. The more effective tools use adaptive computer approaches called artificial intelligence, or machine learning. They can recognize data patterns that typify a given problem and alert the engineer to the possibility of a specific difficulty. They can also "learn" from experienced people, and incorporate that experience into their analyses.

\section{EVIDENCE OF NEED FOR IMPROVED MEASUREMENTS}

ASTM Committee F-1 on Electronics sponsors workshops on measurement issues in semiconductor manufacturing that provide reports describing the need for new measurement standards and the metrology on which they would be based. ASTM F-1 has a planning subcommittee on standard reference materials (SRMs), established in 1989. At its first meeting, in 
addition to developing a list of proposals for SRMs from NIST, the subcommittee decided to start work on consensus-calibrated materials. It has also asked NIST to be the repository for materials used in interlaboratory experiments for establishing the accuracy and bias of new test methods, these materials having a lasting value for several measurement validation purposes. Both of these ASTM activities are valuable sources of industry advice on current needs for measurements, especially relating to materials and in-process topics. SEMI standards committees have discussed needs for measurement work on moisture in gases, contaminating particles, feature size and layer-to-layer registration of patterns, gas and liquid flow, trace impurity levels in chemicals, and thermal properties of semiconductor devices and their packages.

Several technical presentations at a symposium on measurements for the semiconductor industry, sponsored by ASTM, SEMI, and NIST early in 1990, contained lists of quantities for which better measurements are needed. SEMATECH held workshops during 1989 on lithography (pattern production) and in 1990 on film deposition processes that provided much useful guidance. The SRC Technical Advisory Board meets for three days annually to assess the longrange trends in the industry that will define its research agenda. The SRC also held two topical research conferences on temperature measurements and on metrology for semiconductor manufacturing in February, 1990. The reports of these conferences ${ }^{26}$ contain very good current consensus summaries of measurements needed through the end of the century, to the extent they can be identified in detail.

Technical discussions with SEMATECH staff support the need for

improved measurements of feature size and layer-to-layer registration of patterns, thickness and interface characteristics of thin transparent films (including multilayer films), and intensity and spectral distribution of short wavelength ultraviolet light used for exposing photoresist;

calibration services for ultraviolet photometers and for flow-measuring devices;

evaluation of techniques for measuring the concentration and spatial distribution of chemical species in plasma discharges and determination of their chemical reactivity;

reference materials to calibrate instruments that measure the depth distribution of dopants in silicon;

improved understanding of the chemical and physical processes involved in depositing films on surfaces;

improvements in test devices used to assess the execution of many fabrication processes; development of computer aids to detect data patterns indicating out-of-control processing conditions;

standard data systems architectures that allow communication between disparate computer systems and networks effectively and transparently; and

comparisons among several commonly used device modeling codes to determine whether or not the results from the various codes agree.

The development cycle for a new generation of semiconductor devices takes more than a decade, starting with basic research and extending through industrial technology $R \& D$, new manufacturing tool development, and new device manufacturing development to the time when

\footnotetext{
${ }^{26}$ See footnote 5 for a listing of these reports. Distribution of SRC reports is limited to conference attendees, employees of SRC member companies, and faculty members of SRC sponsored research programs.
} 
devices are qualified by customers for their use. At any time, about four such cycles are in process, because new device generations appear in the marketplace about every three to four years. Metrological R\&D needs to take place throughout these cycles.

\section{MEASUREMENTS NEEDED}

Throughout its history, the semiconductor industry has required measurements that were beyond the current state of the art. These needs have been one of the major driving forces on company and university researchers, instrument manufacturers, NIST, and industry standards organizations like ASTM and SEMI to develop new scientific information, tools, and measurement methods. In spite of the impressive number of techniques that now exist, better ones are still needed. There is no apparent end to this continuing demand.

There are, however, three major differences in the needs of today and through the 1990's as compared with those of perhaps a decade ago. One is the very much wider range of technologies now in use by the industry and the consequent broader spectrum of scientific and technical skills needed to address the measurement needs. The second is the greatly increasing difficulty in pushing forward the frontiers of measurement. Detection sensitivities of one part per trillion (a million million) are needed in some analytical measurements. As the devices get smaller, the volume of material to be probed is also smaller. The spatial resolution of many measurements should be, but currently is not, smaller than the minimum feature size of patterns on wafers. These are formidable challenges. Without the needed measurements, the material and equipment suppliers and the device makers often are left groping in the dark in their efforts to improve quality and yield of their products. Third is the greater need for real-time and in-situ measurements.

Measurement techniques are often different for those that are performed in real time, insitu, in-line, or off-line. Real time metrology involves continuous measurement within the process tool and feedback for dynamic control of the process. In-situ measurements are also performed inside the process tool but after the process step is completed. In-line measurements are made on external equipment after the wafer is removed from the process tool; the wafer is returned to the process flow. Off-line measurements are usually more time-consuming and may be destructive; the wafer is generally not returned to the process flow. The first three types of measurement must be non-destructive. Reproducibility ${ }^{27}$ is essential for all of these kinds of measurements. Accuracy ${ }^{28}$ is very desirable for process control and indispensable if technology is to be transferred.

\footnotetext{
${ }^{27}$ A reproducible measurement is one that gives the same result day after day. The result may be wrong, but it is always wrong by the same amount and in the same direction, too high or too low.

${ }^{28} \mathrm{An}$ accurate measurement is not only reproducible, but it is free from error to within a stated uncertainty. Accurate measurements made at various times and places by different instruments having different operators will agree within the accuracy limitations of the instruments being used.
} 


\section{Materials}

High-priority new or improved measurements needed for silicon are listed in Table 12. Lenses used to project the patterns on wafers have a very shallow depth of field (the region of sharp focus), which is approaching one micrometer. This means that the area of the wafer to be printed, now about 0.4 in. square but growing over time, must be at least that flat when mounted on a vacuum chuck. Distortion of the chuck itself as a result of the internal reduced pressure and any external forces must be taken into account.

Table 12

\section{Selected Measurement Needs for Silicon}

\section{Property}

wafer diameter

wafer flatness

wafer thickness

site flatness

site thickness variation

site size

resistivity

resistivity radial uniformity

oxygen content

carbon content

epitaxial layer thickness

sheet resistivity

surface impurity level

surface particle size, max.

particles per wafer, max.

\section{Range}

up to $200 \mathrm{~mm}$

$20 \mu \mathrm{m}$

up to $725 \mu \mathrm{m}$

$<1 \mu \mathrm{m}$

$0.5 \mu \mathrm{m}$

$20 \times 20 \mathrm{~mm}$

$0.001-200 \mathrm{ohm}-\mathrm{cm}$

$0-5 \%$

0-40 ppm

$<200 \mathrm{ppb}$

$1-50 \mu \mathrm{m}$

varies

$<1 \cdot 10^{11} \mathrm{~cm}^{-2}$

$0.1 \mu \mathrm{m}$

5

\section{Uncertainty}

$<0.05 \mathrm{~mm}$

$<1 \mu \mathrm{m}$

$<1 \mu \mathrm{m}$

$<0.1 \mu \mathrm{m}$

$<0.1 \mu \mathrm{m}$

$<0.5 \%$

$<0.5 \%$

$<1 \%$

$<5 \%$

$(0.2 \mu \mathrm{m}+5 \%)$

$<10 \%$

$<1 \cdot 10^{10} \mathrm{~cm}^{-2}$

Source: Principally from Technical Trend of Large Diameter Silicon Wafer II, Masaharu Watanabe, Chairman, Large Diameter Wafer Technology Trend subcommittee of Japan Electronic Industry Development Association, 1990.

The electrical resistivity of the wafer is determined during the crystal growing process by the material producer. It can be varied over an extremely wide range by adjusting the dopant concentration, but its value is tightly specified by the device maker. Typical specified ranges from maximum to minimum value of the wafer center-point resistivity at present are about 5 percent of the nominal value. Currently-available Standard Reference Materials (SRMs) from NIST have an uncertainty of 1.58 percent. These are typically used to calibrate other working standards, which thus are somewhat less precise. These secondary standards are used in turn to calibrate test instruments (having added uncertainties of their own) used to determine the resistivity independently by the buyer and the seller. One can readily see that if the errors introduced by each party are in the wrong directions, the buyer may believe that the material does not meet his specification while the seller believes it does. NIST is working to reduce the uncertainty of the SRMs, but a better way must be found to deliver a calibrated measurement to the points of use without additional uncertainties creeping into the process. 
Oxygen is present in most silicon up to about 40 parts per million (ppm). Its presence at a controlled level of 20 to $30 \mathrm{ppm}$ is useful for reducing wafer distortion during processing and for removing unwanted impurities from the active regions of the wafer. Its concentration is measured by the absorption of infrared light as measured by a spectrophotometer. No NIST SRMs exist for this measurement, though they are in preparation. The commercial situation is similar to that of resistivity; the maximum acceptable uncertainty in oxygen content is very close to the uncertainty of the measurement, given that different spectrophotometers vary somewhat in their calibration. Without suitable SRMs, this variation cannot be removed from the measurement.

Measurements needed for compound semiconductors are listed in Table 13. Wafers of compound semiconductors must be as flat as silicon wafers. In addition, numerous different, specialized measurements are required. Stoichiometry refers to the atomic ratios of the constituent elements, which can be varied at will in compound materials but must be controlled to produce materials with predictable characteristics. Silicon is easy to produce with few, if any, structural defects. This is almost impossible to achieve with compounds, though steady progress is being made. Impurity control is much more difficult in compounds as well, largely because the starting materials are not available in such pure form as those for silicon. Many devices made from compound semiconductors require wafers having extremely complex layered structures. These are made, starting with a uniform substrate, by growing layers having differing composition, doping, or thicknesses. The growth process is capable of changing composition on an atomic layer by layer basis if necessary. Consequently, the control of these three variables is crucial.

Table 13

Selected Measurement Needs for Compound Semiconductors

\section{Property}

stoichiometry

defects

impurities

layers:

thickness

composition

electrical properties

uniformity $\underline{\text { Range }}$

0-100\%

wide

wide

atomic scale, up to few $\mu \mathrm{m}$

$0-100 \%$

wide

\section{Uncertainty}

$0.5 \%$

$2 \%$

$5 \%$

$1 \%$

$1 \%$

$5 \%$

$2 \%$

Gases used in the semiconductor manufacturing process need the measurements listed in Table 14. There are two large groupings of gases, those used in large volumes (nitrogen, oxygen, argon, hydrogen) and a much greater variety of specialized gases used in much smaller quantities. All share these basic measurement needs, being required to be free of particles and moisture and to meet varying specifications for composition and purity. Currently available measurements for all but composition fall short of tomorrow's needs by factors of ten to a thousand. For many special gas mixtures, composition (assay) measurements are not sufficiently accurate as well. Nitrogen and oxygen may economically be produced at the user's plant if the 
volume warrants it. The process involves the liquefaction and subsequent distillation of air in a facility operated by the gas supplier.

\section{Table 14 \\ Measurement Needs for Gases}

$\begin{array}{lll}\text { Property } & \text { Range } & \text { Uncertainty } \\ \text { particles } & \text { down to killer defect* size } & <5 \% \\ \text { moisture } & <1 \text { part per billion } & <10 \% \\ \text { composition } & \text { wide } & <1 \% \\ \text { impurities } & <1 \text { part per billion } & <10 \%\end{array}$

*See Table 9

The list in Table 15 describes the measurements needed for liquid chemicals and water. Large quantities of high-purity water are used in semiconductor manufacturing for rinsing and cleaning. It must meet the same requirements for particles and impurity content as any other chemical. Special requirements apply to biological contaminants (bacteria and organic materials) in addition. Solvents, acids, and photoresists each have unique analytical and physical properties that must be measured. The majority of these measurements are beyond the state of the art today.

Table 15

Measurement Needs for Liquids

Particles

smaller than killer defect* size

number, size distribution needed

new techniques needed below $0.2 \mu \mathrm{m}$

Assay

principal constituents, to $1 \%$ of amount

Impurities

unwanted materials, below ppb levels

example for water:

iron $<0.01 \mathrm{ppb}$

silica $<1 \mathrm{ppb}$

*See Table 9

Solid materials, such as metal deposition sources and packaging materials, also require measurements. Metals are used to form the conducting patterns that interconnect the individual devices that comprise the integrated circuit. These are deposited either by physical processes such as evaporation (mostly for pure metals, not alloys), by sputtering, or by chemical vapor deposition. In the latter case, the metal is incorporated in some chemical compound that is decomposed to produce the metal film. These films, produced by either physical or chemical means, are subsequently patterned using a lithography process. Regardless of the method of film 
formation, the important variables to control are the metal purity and composition (if it is an alloy), film thickness and electrical conduction properties, and the grain size of the crystallites in the film. All of these must be measured. The properties of the source materials, such as solid metals for physical deposition and gases or liquids for chemical deposition, have direct effects on the properties of the deposited films. Measures for the essential characteristics of the starting materials and of the deposition processes themselves all need to be developed.

Metals are also used for bonding wires to connect the integrated circuit to the parts of the package that form the external connections, and for parts of the package assembly. Bonding wire is tailored to specific processes and equipment, and must have closely controlled composition, diameter, temper, surface finish, and cleanliness. These wires typically range in diameter from 25 to $75 \mu \mathrm{m}$ (0.001 to 0.003 in.). For plastic packages, a metal stamping called a lead frame is the other metallic part. This rather intricate stamping includes a pad on which the integrated circuit chip is mounted, slender fingers to which the bonding wires from the chip are attached, and an external frame (hence the name "lead frame") that holds everything together until the package is molded. Then the frame is trimmed away. Lead frames have less demanding requirements for purity, though they must be clean. The important attributes of lead frames are their composition, dimensions, flatness, and surface finish. Analytical measurements for bonding wires are critical, but some attributes are not well understood. It is conjectured that some minor constituents of bonding wire reside in the grain boundaries of the metal, where they affect the bonding properties. All that really is known is that different batches of wire having apparently the same composition do not always have the same handling and bonding properties.

Plastic molding compounds are specialized for semiconductor use, having especially low levels of ionic constituents. If present, such materials contribute to corrosion of the lead frame and the metal patterns on the chip, particularly in moist environments. In addition, the molding properties, such as the viscosity of the material while being molded, must be closely controlled. If the compound is too viscous, the positions of the fine bonding wires can be disturbed and, in extreme cases, the wires can be broken. Finally, the molding compound must have good thermal conduction properties. Plastics at best are poor thermal conductors as compared with metals, but because the plastic part of a package has a far larger surface area than the metal parts and is in more intimate contact with the chip, a substantial part of the heat generated in the chip passes through the plastic to the external environment.

All of these materials must also have extremely low levels of radioactive impurities. Traces of radioactive elements pervade everything, but at such low levels that they are usually of little concern. But the regions of chips that store information are extremely small, and the number of electrons representing the information is also minuscule. Alpha particles, the products of certain radioactive decay processes, create large numbers of electrical charge carriers if they travel into the silicon. These cause loss of bits of stored information by filling the storage locations with unexpected and unwanted electrical charges. The damage is not permanent, but the changes are real and often have serious consequences. Radioactive elements do not ordinarily enter the chip-making processes because of the chemistry and physics of the processes, but if present in the surrounding materials they can cause these transient upsets of stored information. 


\section{Processes}

Most processes require a much more detailed list of measurements than can be given here. An example of what must be known about a plasma etching process to provide improved process control is given in Table 16. This information would be provided to a computer that models this process and predicts the listed output parameters. At the present, too little is known about plasma processes to implement such a system. The measurement tools would, in most cases, be specially designed to fit into the process chamber and not be damaged by the effects of the process.

Table 16

\section{Plasma Process Information Requirements}

\section{Input Variables}

Material Attributes

wafer resistivity

wafer reflectivity

wafer weight

gas ionization

etch parameters (at right)

Environmental Variables

temperature

\section{Process Variables}

plasma parameters (at right)

machine parameters (at right)

wafer temperature value

wafer temperature uniformity

species concentration in

the plasma

pressure

flow

Etch Parameters
anisotropy
selectivity
etch rate
etch rate uniformity
Plasma Parameters
electron temperature
electron density
ion temperature
neutral density
sheath potential

Machine Parameters

power

pressure/vacuum

wafer temperature

wafer potential

flow rates

residence time

electrode spacing

DC self bias

film thickness

end point detection

electrode etch

\author{
Output Variables \\ film thickness \\ critical dimension \\ etch depth \\ wafer weight
}

Instrumentation $^{1}$

vacuum diagnostic system

RF monitor

optical emission spectroscope

Langmuir probe

bulk ion temperature and

residual gas analyzer

forward looking IR

laser-induced fluorescence

voltmeter, ammeter

pressure gauges

flowmeters

interferometer

reflectometer

weighing instrument

${ }^{1}$ Listed instruments do not relate to the variables immediately to their left.

Source: Richmond B. Clover, in Proc. SRC Topical Research Conference on Metrology for Semiconductor Manufacturing, Santa Fe, NM, Feb. 21-22, 1990; p. 62.

Similar process information requirements, but substantially different in their details, exist for many other deposition and removal processes, such as epitaxial layer growth, chemical vapor 
deposition (which comes in several distinct varieties), plasma deposition, reactive ion beam etching, etc. Obtaining the basic chemical reaction and physical properties data is difficult, requiring the use of the most advanced scientific measurement and diagnostic tools. Most of these processes have been developed about as far as possible on an empirical basis. Further progress depends on substantially improved knowledge of these process details and the development of computer models that can translate the measurements made in-situ into process control actions that improve productivity.

Lithography (the process of making patterns), already a demanding process, will require pressing optical tools to their limits by the end of the decade, as shown in Table 17. The measurements available now are unsatisfactory and inadequate to meet future needs. Measurements of feature sizes on wafers cannot be made to the desired accuracy. The industry is making do with instruments that are moderately repeatable but of uncertain accuracy. Reaching the goals in the table will be extremely difficult. To appreciate the meaning of the numbers, one has to recognize that the spacing between silicon atoms is $0.0004 \mu \mathrm{m}$, or 0.4 nanometers $(\mathrm{nm})$. Thus the machines that produce the patterns must be able to position them with an accuracy of 125 atomic spacings in both $\mathrm{x}$ and $\mathrm{y}$ dimensions within a tenth of a second, level the wafer to fit within the focal plane, focus to well within a micrometer of the right place, expose the wafer, and repeat this cycle every second for 16 hours a day in a production environment. The demands on the automatic metrology systems that must be built into these machines to control their operation reliably are truly staggering.

Table 17

Measurement Needs for Lithography in Year 2000

Property

Patterns:

smallest dimension

overlay error

killer defect size

Radiometry:

light intensity

wavelength (for lasers)
Target Value

$0.15 \mu \mathrm{m}$

zero

$0.03 \mu \mathrm{m}$
Uncertainty

$\pm 0.03 \mu \mathrm{m}$

$\pm 0.05 \mu \mathrm{m}$

Instruments used to measure the light intensity and exposure time of today's lithography exposure tools are inaccurate. This has been shown by interlaboratory experiments with a major semiconductor manufacturer and with SEMATECH. An ultraviolet radiometry calibration service is being developed by NIST for the light wavelengths now in use. Mercury arc light sources are universally used now, but future exposure tools will need shorter wavelength, brighter sources than mercury arcs. Various types of lasers are under development for this purpose. One promising candidate emits light having a nominal wavelength of 248 nanometers $(\mathrm{nm} ; 1 \mathrm{~nm}=0.001 \mu \mathrm{m})$. Basic optical theory shows that the focal length of lenses varies in such a way with the wavelength of the light that some means of wavelength stabilization will be necessary if the lens is to have a known focal length. This means that the wavelength must be 
measured with considerable accuracy. As new exposure tools for finer geometries are developed, these measurements will need extension to cover shorter wavelengths as well.

Film deposition and removal processes will need many improved measurements, as Table 18 shows. Existing equipment measures some of these variables, such as deposition rate, but indirectly. To reduce process variations, it is much preferable to measure as many of these properties as possible in real time. Film composition, thickness uniformity, and step coverage (maintenance of uniform film thickness and integrity at places where the underlying surface changes its height) are all measured outside the process machine now. Knowledge of surface chemistry and physics will allow key measurable properties of the process to be identified, which will allow more of these measurements ultimately to be made in real time. In film removal, it is necessary to take away parts of an existing film completely and cleanly without eroding the underlying surface. Nearly vertical edges should remain to define the islands of remaining film that were not removed. The process should proceed at the same rate across the entire wafer. To avoid etching the underlying layer, the chemistry of the process is chosen such as to react readily with the material to be etched and not with the underlying film, as far as that is possible. That is the differential etch rate.

\section{Table 18 \\ Measurement Needs for Film Deposition and Removal Processes}

Film formation
deposition rate
composition
surface reactions
thickness control
uniformity
step coverage

Film removal

removal rate

uniformity

differential etch rates

end point detection

\author{
Film thickness \\ single \\ multiple \\ interlayers \\ properties
}

More sophisticated off-line measurements are used to verify that the process produces the desired films, to test their electrical and optical properties, to examine the properties of the interfaces between layers, and to make measurements on more complex structures. Such information is used to establish accurate process performance data for use in process modeling and improvement programs.

The connection between the silicon and the metal patterns that interconnect individual circuit elements is crucial for proper integrated circuit performance. These connections are typically made through holes in insulating overlayers. The holes are of about the same diameter as the smallest pattern dimension and may be several times that deep. Special processes are often used to form metal plugs in these holes that are then interconnected in a later step. A chip will contain several million of these holes that must all be successfully plugged with a metal that makes good electrical contact with the silicon. This process will become more demanding as dimensions continue to shrink.

\section{General purpose techniques}

Some measurements must be made in many places throughout a semiconductor plant. Particle detection, counting, and sizing is one such measurement. An example of the desired 
characteristics of one type of particle detection system is given in Table 19. This one would be optimized for measurements inside equipment in a vacuum environment. Different types of particle detection instruments are used for measurements in gases or liquids, or on wafer surfaces. Each of these applications constrains the design of the equipment differently, including imposing different limits on the minimum size particles that can be detected. The size limit today is $0.2 \mu \mathrm{m}$ if the particle dimension must be known. Smaller particles can be detected but without knowledge of their size.

\section{Table 19 \\ In-Situ Particle Detection Objectives}

Large area detection

Detection limit

Sizing capability

Real-time detection

Inside the chamber

In pumping line

On-wafer monitor

Optical detection

Low cost
$>100 \mathrm{~cm}^{2}$ desirable, $>10 \mathrm{~cm}^{2}$ a good start

$<0.05 \mu \mathrm{m}$ desirable, certainly $<0.1 \mu \mathrm{m}$

nice feature, but not essential

essential for real-time control

needed to locate particle sources

acceptable, but not as good as inside the chamber

ideal, probably too expensive and $<0.1 \mu \mathrm{m}$ not possible

nice, but $<0.1 \mu \mathrm{m}$ not possible

$\$ 5 \mathrm{~K}-\$ 15 \mathrm{~K}$ for real-time process control

Source: R.A. Bowling and G.B. Larrabee, in Proc. SRC Topical Research Conference on Metrology for Semiconductor Manufacturing, Santa Fe, NM, Feb. 21-22, 1990; p. 475.

Another process measurement technique involves test structures that assess how well various process steps were executed. (See Table 20.) Test structures are tiny device-like measuring tools that are made by the same processes that make integrated circuits. They are inserted in small spaces on the wafer, such as between the IC chips in the track to be taken by the diamond saw when the chips are separated. The test structures are designed to measure such parameters as the electrical properties of films, electrical contact between various layers, width of conducting lines, the properties of individual transistors having the same geometry as those in the integrated circuit, and many other process-dependent characteristics that can be evaluated by electrical means. Since the test structures are processed in the same way as the rest of the wafer, these measurements are a reliable way of characterizing individual process steps. They do not, however, deliver the information until relatively late in the process after the wafer has been given its metal contacts, because it is not possible to make electrical connections to the test structures before then.

Test structures can also be used to evaluate the performance of heavily-stressed parts of the circuit to determine if they are likely to fail in service or not. The physical limits of performance of metals for conductors on the chip and of insulating layers such as gate oxides are being approached. As devices become smaller, other parts of the circuit will no doubt be exposed to such extreme stresses. Test structures for characterizing the electromigration failure mechanism of metals have been developed along with standard tests using them to forecast the reliability of 
Table 20

\section{Measurement Needs for General Process Evaluation}

Process evaluation

test structures

in-situ measurement tools

reliability prediction

Process variables
temperature
flow
pressure
residual gas analysis

Process information

data transmission and management data screening methods

the chip. New test structures can be devised for other such measurements as they become needed. The objective is to assure that the IC was made right from the beginning and will not fail. The approach to reliability assurance has been to test large numbers of parts under extreme conditions designed to accelerate failure mechanisms. This is time-consuming and expensive, and not entirely satisfactory for technical reasons as well. Predictive testing has the potential to change this situation greatly for the better.

Many process variables are common to a large number of kinds of manufacturing tools. The temperature of the wafer during processing must be accurately known because of its influence on the rate at which chemical and physical events occur. There are serious limitations in measuring temperature accurately, because the temperature sensing device cannot be allowed to contact the wafer for fear of contamination or physical damage. Errors of $200^{\circ} \mathrm{C}$ at temperatures of $800^{\circ} \mathrm{C}$ are common in rapid thermal processing equipment that rapidly raises the temperature of a single wafer to high temperatures, holds a temperature briefly, and then cools the wafer quickly. The purpose is to accomplish a thermal treatment with a minimum time at high temperature, to limit undesired diffusion effects. The high rate of change of temperature greatly complicates the measurement problem. Even in equipment that operates at constant temperature the errors in temperature measurement can be intolerably large.

Flow rates of gases and liquids also offer difficulties. Calibrations are done in terms of standard fluids such as air and water. When the application is for metering other fluids, particularly gases, errors are common. Mass flow controllers use the thermal properties of the gas to measure flow, and these vary significantly. Calibrations using the actual gas to be measured are not practical because there are so many different kinds, some of which are either corrosive, toxic, or both. Errors are reported up to 20 percent.

Measurements of pressure in vacuum systems and the analysis of the gases present in vacuum systems are strongly affected by the presence of reactive chemical species. These problems were uncovered in collaborative work between NIST and Intel and are probably not widely appreciated. The conditions that lead to these errors are common in semiconductor processing environments. Ways to solve the problem are unclear at present.

Getting the right information to the right person or computer is a growing problem; the exploding volume of data (see Table 11) only exacerbates the issue. A wide variety of computers, in tools, in instruments, and in networks, must communicate. Ways to do this that are independent of the kind of computer have been developed, for instance, in the NIST Automated Manufacturing Research Facility. Integration of all of the computer-aided operations from design and engineering through manufacturing and test and on to management and marketing is the goal. In addition, the need to communicate must be kept in mind. Simply delivering data is not enough. The right information must be delivered to the right person or computer or machine in ways that make it possible for each of these information users to do his, her, or its job right. This means enough information in the right form and on time. It also means accurate 
information; erroneous information from poor measurements or other noisy sources is worse than useless.

Device design and verification problems and those related to packaging are listed in Table 21. The device-related issues provide the foundation for integrated circuit design. At numerous times in the past, when new devices of smaller scale were applied in ICs, corrections to the computer codes for device models have been necessary. Reasonable physical and mathematical assumptions that were made to keep the computer code simpler have turned out not to be reasonable at the smaller scale. Such problems are discovered when the predictions of device performance do not match measurements of performance. Reasons for the discrepancies must then be discovered and the model corrected. This is not a trivial task, usually involving advances in the theory of device operation and sometimes significant new understanding of fundamental solid-state physics.

Table 21

\section{Measurement Needs for Devices and Packages}

Devices:

shrinking scale raises new problems in

physics of device operation

basic theory, in some cases

use of models for device design

need to develop

theory as needed

corrections to existing models

changes need verification

deliver results to industry

\author{
Packaging: \\ physical properties \\ materials and interfaces \\ polymers, metals, ceramics \\ electrical properties \\ dielectric characteristics \\ metal conductivity \\ chemical properties \\ polymer degradation mechanisms \\ metal corrosion \\ thermal properties \\ materials \\ interfaces \\ anisotropy \\ failure mechanics
}

Note: The number of connections will reach over 1000 by the mid-1990's.

As integrated circuits have become more complex and powerful, demands on the package have increased. More connections to the chip are required in many cases, leading to the need for more than 1000 external connections to a single logic IC in the latter half of the decade. Not all chips will require this many connections, but quite a few will. Larger chips also generate more heat, adding increased thermal dissipation burdens to large packages. More subtly, differences in thermal expansion between different materials will cause problems. Silicon has a remarkably small thermal expansion coefficient, about a fifth of that of most metals. Attaching a large silicon chip to a metal heat-conducting member will mean the adoption of techniques previously needed for large power devices, but in a flat package configuration that is different from that used for power devices. Plastics generally expand even more than metals. New package configurations and low-expansion plastics will be needed to prevent the differences in thermal expansion from placing excessive stresses on any part of the assembly. Measurements of materials properties, how well plastics, metals, and semiconductors bond to one another, and 
what causes package materials to fail are all issues. These data are needed for new and larger packages to be designed and manufactured successfully.

To realize the performance advantages of new chips, new packages with appropriately high performance must be developed in parallel with new chip designs. The knowledge base needed to design such packages approaches that needed for designing the chips. Improvements in packaging require extensive new knowledge of the properties of dozens of materials and material interfaces. Without this knowledge, package performance and reliability will limit the abilities of advanced devices to achieve their intended potential. 



\begin{tabular}{|c|c|c|}
\hline \multirow[t]{3}{*}{$\begin{array}{l}\text { NIST-114A } \\
\text { (REV. 3-90) }\end{array}$} & \multirow[t]{3}{*}{$\begin{array}{r}\text { U.S. DEPARTMENT OF COMMERCE } \\
\text { NATIONAL INSTITUTE OF STANDARDS AND TECHNOLOGY }\end{array}$} & $\begin{array}{l}\text { 1. PUBUCATION OR REPORT NUMBER } \\
\text { NISTIR } 4653\end{array}$ \\
\hline & & 2 PERFORMING ORCANIZATION REPORT MUMBER \\
\hline & & $\begin{array}{l}\text { 3. PUBUCATION DATE } \\
\text { SEPTEMBER } 1991\end{array}$ \\
\hline
\end{tabular}

Metrology for the Semiconductor Industry

5. AUTHOR(S)

Robert I. Scace

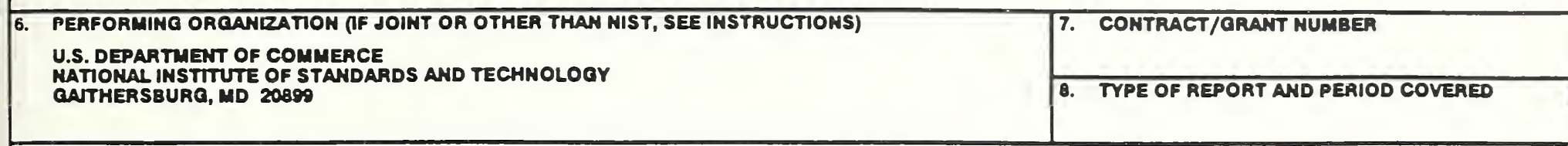

9. SPONSORINQ ORGANIZATION MAME AND COMPLETE ADDRESS (STREET, GTY, STATE, ZP)

10. SUPPLEMENTARY NOTES

11. ABSTRACT (A 200-WORD OR LESS FACTUAL SUMMARY OF MOST SIONIFICANT INFORMATION. IF DOCUMENT INCLUDES A SIONIFICANT BIBLOGRAPHY OR UTERATURE SURVEY, MENTION IT HERE)

The metrological needs of the semiconductor industry and its supporting materials and manufacturing equipment industries for the 1990's are set forth. The information in this report derives from technological workshops sponsored by the American Society for Testing and Materials, NIST, SEMATECH, Semiconductor Equipment and Materials International, and the Semiconductor Research Corporation; fron industry information sources such as Dataquest and VISI Research; from NIST colleagues; and from personal discussions with many others in the field. The data from these sources have been analyzed for their implications for measurement science and technology, on which this report focuses. It contains a brief introduction to the economic significance of the semiconductor industry, an overview of the relevant technologies, their development trends and the metrological needs thus implied, and evidence of needs expressed by sources outside of NIST. The report deals with the needs for measurements of all kinds, but intentionally does not discuss the means by which these may be met. The text is also to be published as one chapter in a more comprehensive assessment covering the electronics industry as a whole.

12. KEY WORDS (6 TO 12 ENTRIES; ALPHABETICAL ORDER; CAPTAUZE OMLY PROPER MAMES; AHD SEPARATE KEY WORDS BY SEMICOLONS)

integrated circuits; measurements; metrology; process control; semiconductor devices; semiconductor manufacturing; semiconductor materials

1

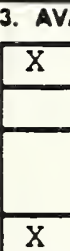

\section{ABITY}

UHUMTED

FOR OFFICLAL DISTRIBUTION. DO NOT REEASE TO NATIONAL TECHMICAL INFORMATION SERVICE (NTIS).

ORDER FROM SUPERINTENDENT OF DOCUMENTS, U.S. OOVERMMENT PAINTING OFFICE, WASHINOTON, DC 20402

ORDER FROM MATIONAL TECHMICAL IMFORMATION SERVCE (NTIS), SPRIMGFIED, VA 22161.

14. NUMBER OF PRINTED PAGES

46

15. PAICE

$\mathrm{AO} 3$ 


